\title{
Bottom Reinforcement in Braced Excavations: Coupled Analysis and New Method for Basal-Heave Stability Study
}

\author{
J.L. Borges, R.M. Santos
}

\begin{abstract}
Soil-cement bottom reinforcement is commonly used in braced excavations in soft soils, so that ground displacements can be reduced and excavation safety against bottom failure increase. However, there is a lack of studies in the literature regarding such reinforced excavations in which the stability against bottom heave is analysed through mechanical-hydraulic coupled modelling. In the paper, in order to contribute to overcome such deficiency, a braced excavation in soft soil, incorporating a jet-grout base slab, is analysed. A finite element code, which incorporates the above-mentioned features, is used and a new method for basal stability analysis - which utilizes the numerical results obtained by the finite element code - is proposed and applied. Two cases of the same problem, with and without soil-cement bottom slab, are compared.
\end{abstract}

Keywords: basal-heave stability, consolidation, coupled analysis, jet-grout slab, soft soil, strutted excavation.

\section{Introduction}

The construction of deep excavations in soft soil deposits has been one of the major challenges for geotechnical engineers. In such excavations, settlements of the supported ground are usually very large, over $1-2 \%$ of the excavation depth, as reported by Peck (1969) for excavations constructed before the seventies.

However, in the last decades, several new technologies have been considered to improve the control of the induced movements in such excavations. Matos Fernandes $e t$ al. (2012) summarized several procedures that can be used in practice to control the displacements for deep excavations in soft ground, by considering the use of: (i) stiff (reinforced concrete) walls, to reduce the wall deflection due to bending; (ii) early installation of the first level of supports (struts or pre-stressed anchors, typically), to prevent significant displacements of the upper part of the wall working as a cantilever; (iii) connections between struts and the wall carefully designed and constructed, to ensure that the effective strut stiffness corresponds to a high percentage of its theoretical value; (iv) impermeable walls, to avoid lowering of the water table in permeable layers, which induces consolidation settlements in soft clay strata, as well as to prevent settlements associated with internal erosion of sandy strata; (v) ground treatment before excavation, to support the wall and control displacements under the excavation base at each stage; (vi) walls with tips embedded in the bedrock, to control the displacements under the excavation base; (vii) pre-stressed struts, to increase the effective strut stiffness, closing gaps in the strut-wall connections, as well as to recover part of the displacements induced by previous excavation stages; (viii) staged excavation limited to a min- imum at each stage, to avoid over-excavation that reduces the support effect provided by the struts or ground anchors.

With regard to the use of ground treatment techniques, one possible solution consists in extending the wall below the excavation base and, before excavation, constructing a soil-cement base slab (using jet grouting or deep soil mixing technologies, for instance) to support the wall below the excavation bottom (Mateus, 2010).

Another important issue that needs to be analysed for braced excavation projects in soft clays is the basal-heave stability, for the lateral earth support system is often controlled by stability requirements. Different methods have been used in practice to perform stability calculations for braced excavations, which basically are based on either limit equilibrium approach (Terzaghi, 1943; Bjerrum \& Eide, 1956; Clough \& Hansen, 1981; O’Rourke, 1992; Su et al., 1998; Ukritchon et al., 2003) or finite-element analysis (Faheem et al., 2003; Faheem et al., 2004; Cai et al., 2002).

Another pertinent question when excavations are undertaken in saturated clayey soils is the generation of increments of pore pressure during the excavation period and their dissipation after that period (consolidation). After construction, there are pore pressure gradients in the ground that determine a consolidation process. This process is dependent on both the magnitude of pore pressure increments at the end of excavation and the long-term hydraulic conditions. In some cases, settlements of the supported ground increase with time in response to the consolidation, the long term conditions being more unfavourable than those at the end of the excavation period (Borges \& Guerra, 2014; Santos, 2014; Monteiro, 2011; Alves, 2012;

José Leitão Borges, Ph.D., Assistant Professor, Departamento de Engenharia Civil, Faculdade de Engenharia, Universidade do Porto, Rua Dr. Roberto Frias, 4200-465 Porto, Portugal. e-mail: leitao@fe.up.pt.

Rita Marialva Santos, M.Sc., Faculdade de Engenharia, Universidade do Porto, Rua Dr. Roberto Frias, 4200-465 Porto, Portugal. e-mail: ritamarialva@ gmail.com. Submitted on August 7, 2019; Final Acceptance on May 26, 2020; Discussion open until September 30, 2020.

DOI: $10.28927 /$ SR.432199 
Guerra, 2009). Therefore, realistic analyses that take into account the consolidation effect by performing fully mechanical-hydraulic coupled analyses (Potts et al., 1997; Borges \& Guerra, 2014; Costa et al., 2007; Borges \& Alves, 2014) are strongly recommended in many cases, despite the practical importance of more simplified studies such as undrained total stress approaches.

In the literature, there is a lack of studies of deep braced excavations in soft soils in which the three abovementioned issues are simultaneously considered, namely: consolidation effect through mechanical-hydraulic coupled analysis; ground treatment below the excavation base; and basal-heave stability analysis considering the effect of the consolidation.

In the present study, in order to overcome such deficiency, a strutted excavation in soft soil with a jet-grout base slab is analysed. A finite element code is used and a new method for basal stability analysis is proposed, utilizing the numerical results obtained by the finite element program. Comparisons with the classical limit equilibrium methods of Terzaghi (1943) and Bjerrum \& Eide (1956) are included. Two cases of the same problem, with and without the soil-cement bottom slab, are compared.

\section{Finite Element Code}

The finite element code utilized in the present study was developed by Borges (1995) and incorporates, among other features, fully mechanical-hydraulic coupled analysis (Biot consolidation theory) (Borges, 1995; Lewis \& Schrefler, 1987; Britto \& Gunn, 1987) and the $p-q-\theta$ critical state model for soil constitutive behaviour simulation (Borges, 1995; Lewis \& Schrefler, 1987). The initial version of the program was presented in 1995, and several improvements were subsequently developed, including a 3-D coupled analysis version (Borges, 2004).

In the $p-q-\theta$ model - which is an extension of the Modified Cam-Clay model into the three-dimensional stress space using the Mohr-Coulomb failure criterion - the parameter that defines the slope of the critical state line, $M$, is not constant (as happens in the Modified Cam-Clay model), but depends on the angular stress invariant $\theta$ and the effective friction angle, $\phi$, as follows:

$$
M=\frac{3 \sin \phi^{\prime}}{\sqrt{3} \cos \theta+\sin \phi^{\prime} \sin \theta}
$$

This defines the Mohr-Coulomb criterion when $M$ is introduced in the equation of the critical state line

$$
q=M \cdot p^{\prime}
$$

where $p^{\prime}$ is the effective mean stress and $q$ the deviatoric stress. In the principal effective stress space, for an arbitrary state $\left(\sigma_{1}^{\prime}, \sigma_{2}^{\prime}, \sigma_{3}^{\prime}\right)$, where $\sigma_{1}{ }_{1}, \sigma_{2}^{\prime}$ and $\sigma_{3}^{\prime}$ are the principal effective stresses, the angular stress invariant $\theta$, introduced by Nayak and Zienkiewicz (1972), measures the orientation of the projection of the vector $\left(\sigma_{1}^{\prime}, \sigma_{2}, \sigma_{3}^{\prime}\right)$ on the plane that is normal to the space diagonal $\left(\sigma_{1}^{\prime}=\sigma_{2}{ }_{2}=\sigma_{3}{ }_{3}\right.$ axis).

This is an important feature of the $p-q-\theta$ model, for the soil critical state depends on $\theta$, as shown by triaxial and plane strain tests (Lade \& Duncan, 1973; Mita et al., 2004). Drucker-Prager is the failure criterion of the Cam-Clay and Modified Cam-Clay models and does not depend on $\theta$. Numerical and laboratorial results presented by several authors (Potts \& Zdravkovic, 1999; Mita et al., 2004) showed that strain-stress behaviour of the soil is much better simulated if the slope of the critical state line is defined according to the Mohr-Coulomb criterion, which happens in the $p-q-\theta$ model. In excavations, where different types of stress-path occur (in different areas of the ground), which correspond to different values of $\theta$, the use of the $p-q-\theta$ model is particularly pertinent.

Figure 1a shows, in the principal effective stress space, the yield and critical state surfaces of the $p-q-\theta$ model. In the $p^{\prime}-q$ plane, the yielding function is an ellipse (Fig. 1b) and, depending on the over-consolidation ratio, the $p-q-\theta$ model simulates hardening behaviour or softening behaviour. Hardening occurs in normally consolidated or lightly over-consolidated clays while softening occurs in moderately to strongly over-consolidated clays.

The finite element code has been validated against field measurements and used to analyse a wide range of geotechnical structures involving consolidation. With regard to embankments on soft ground, Borges (1995) com-

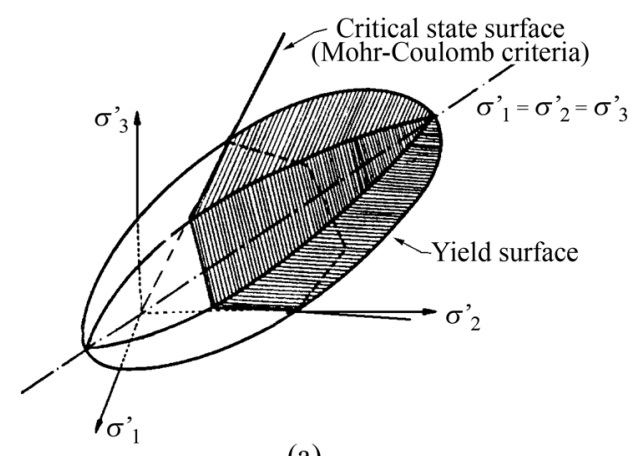

(a)

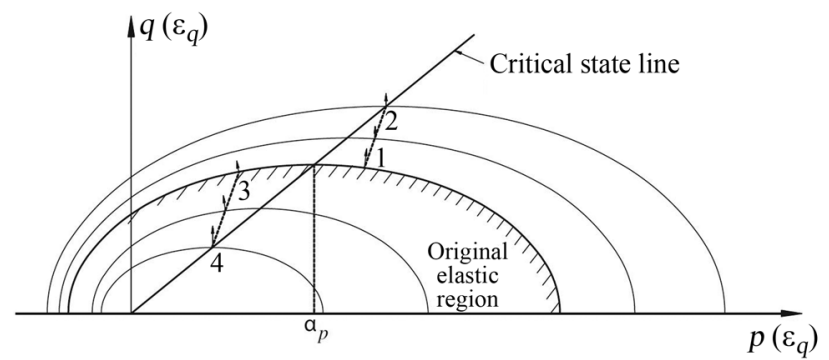

(b)

Figure 1 - Yield and critical state surfaces of the $p-q-\theta$ critical state model in (a) principal effective stress space and (b) $p^{\prime}-q$ space. 
pared results of two geosynthetic-reinforced embankments, one constructed up to failure (Quaresma, 1992) and the other observed until the end of consolidation (Yeo, 1986; Basset, 1986a,b). The accuracy was considered adequate in both cases. Very good agreements with field measurements were also observed in an embankment on soft soils incorporating stone columns (Domingues, 2006) and in a braced excavation in very soft ground (Costa et al., 2007; Costa, 2005), an excavation carried out in the City of San Francisco, presented by Clough \& Reed (1984), to install a large sewer culvert. Others studies of braced excavations in soft soils were also performed using the same finite element code (Borges \& Guerra, 2014; Borges \& Alves, 2014; Santos, 2014; Monteiro, 2011; Alves, 2012; Barros, 2015; Pinto, 2011; Azevedo, 2010; Guerra, 2009).

\section{Stability Analysis Against Bottom Heave}

\subsection{Preamble}

In current practice, two categories of methods have been used to perform stability calculations for braced excavations (Ukritchon et al., 2003): (1) limit equilibrium methods; (2) finite-element methods (FEM). The models proposed by Terzaghi (1943), Bjerrum \& Eide (1956), Clough \& Hansen (1981), O'Rourke (1992), Su et al. (1998) and Ukritchon et al. (2003) are of the first category.

Traditionally, the two most quoted methods for analysing bottom heave stability have been the limit equilibrium approaches based on Terzaghi (1943) and Bjerrum \& Eide (1956). The latter, which actually stems from Skempton (1951) and was calibrated against observed bottom heave failures, is based on the similarity between the bearing capacity of a deeply embedded footing and a bottom heave failure of an excavation.

Figure 2 shows the assumed failure surfaces for the Terzaghi (1943) and Bjerrum \& Eide (1956) methods when the wall is embedded below the excavation base. In this

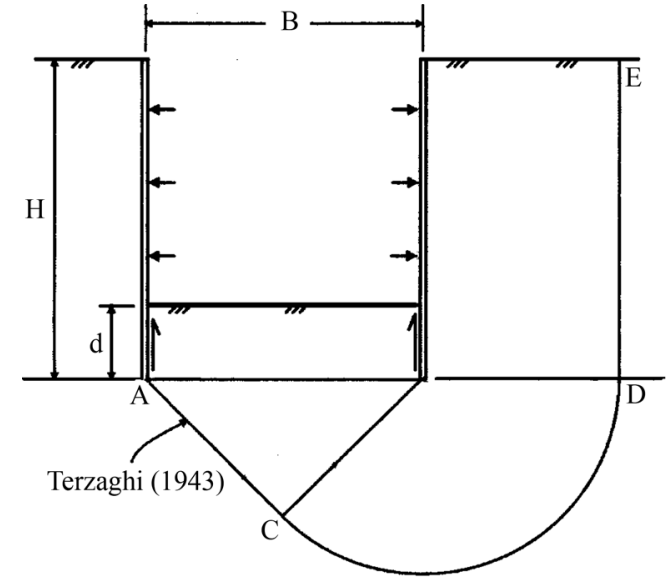

(a) case, the value of the safety factor $F$ is given by Eqs. 3 and 4 , respectively for Terzaghi (1943) and Bjerrum \& Eide (1956) methods:

$$
\begin{gathered}
F=\frac{(2+\pi) s_{u}+\gamma d+\frac{2 d s_{a}}{B}}{H\left(\gamma-\frac{\sqrt{2} s_{u D E}}{B}\right)} \\
F=\frac{N_{c} s_{u}+\gamma d+\frac{2 d s_{a}}{B}}{\gamma H}
\end{gathered}
$$

where $s_{u}$ is the average strength of the soil along the failure surface below the tip of the wall (lines ACD and ACDE in Figs. $2 \mathrm{a}$ and $2 \mathrm{~b}$, respectively), $s_{u D E}$ is the average strength of the soil along line DE for the Terzaghi method (Fig. 2a), $s_{a}$ is the average strength of the soil-wall interface on the embedded depth $d, \gamma$ is the unit weight of soil, $H$ is the vertical length of the wall, $B$ is the width of the excavation, $d$ is the embedded depth of the wall below the excavation base and $N_{c}$ is the bearing capacity factor, which depends on the values of $H, B$ and $L$ (horizontal length of the excavation), incorporating the effect of the soil strength above the wall tip and the effect of the finite length $(L \neq \infty)$ of the excavation.

Despite their traditional importance, it should be mention that the Terzaghi (1943) and Bjerrum \& Eide (1956) methods were developed before the introduction of stiffer wall systems (such as reinforced concrete diaphragm walls) and ignore, for example, the effect of ground treatment when a soil-cement slab is constructed below the excavation base. In other words, when different lateral earth support systems are considered, different stress redistributions occur within the soil; such stress redistributions, which can only be captured by more complex methods (such as finite element analysis), influence the overall stability of the structure, and are

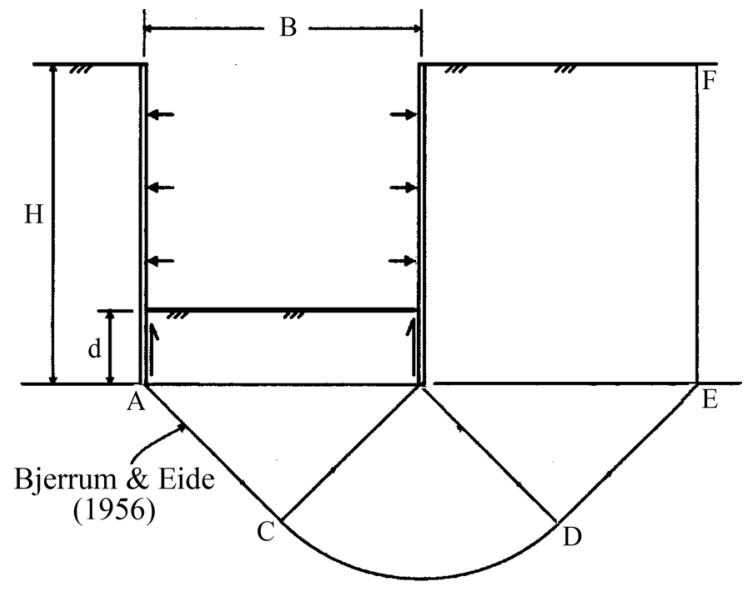

(b)

Figure 2 - Failure surfaces for basal-heave stability analysis of: a) Terzaghi (1943) method; b) Bjerrum \& Eide (1956) method. 
not taken into account in the two above-mentioned methods, as shown below (Section 5).

A second category of methods for calculating basalheave stability is based on finite-element analyses (Faheem et al., 2003; Faheem et al., 2004; Cai et al., 2002) with formulations that are similar to those of the finite-element methods for slope stability analysis, widely accepted in the literature for many years.

With regard to slope stability analysis, two types of finite-element methods have been used in practice: (i) the "strength reduction method" (SRM) and (ii) the "enhanced limit slope stability method" (ELSM) (Liu et al., 2015).

In the SRM, the safety factor is evaluated by the gradual reduction of the shear strength parameters (cohesion, $c$, and friction angle, $\phi)$ of the soil, inducing the divergence (failure) of the nonlinear analysis (Faheem et al., 2003). Reduced shear strength parameters $\left(c_{F}\right.$ and $\left.\phi_{F}\right)$ will replace the real values of $c$ and $\phi$ in the shear strength equation of the Mohr-Coulomb criterion $\tau_{F}=c_{F}+\sigma \tan \phi_{F}$, where $c_{F}=c / F, \phi_{F}=\tan ^{-1}(\tan (\phi) / F)$ and $F$ is the safety factor.

On the other hand, the ELSM uses the finite-element analysis with the real values of the shear strength parameters of the soil and searches for the critical slip surface with the minimum value of $F$. In a 2D-FEM analysis, for an arbitrary slip surface $L$, the potential failure line is divided into small line segments, each one located inside of only one element of the 2D-FEM mesh, and the safety factor $F$ is defined as follows (Borges \& Cardoso, 2002; Borges, 2008):

$$
F=\frac{\sum_{i=1}^{N} \tau_{f_{i}} l_{i}}{\sum_{i=1}^{N} \tau_{i} l_{i}}
$$

where $\tau_{i}$ - acting shear stress at the $i$-segment; $\tau_{f i}$ - soil shear strength at the $i$-segment; $l_{i}$ - $i$-segment length; $N$ - number of mesh elements intersected by the failure line.

While the SRM is associated to the Mohr-Coulomb model, more complex constitutive models can be used in the ELSM, such as, for example, critical state models for clays.

In braced excavations, several authors have calculated the basal-heave stability through finite-element analyses, mainly using formulations of the "strength reduction method" (SRM) (Faheem et al., 2003; Faheem et al., 2004; Cai et al., 2002).

A new method for basal-heave stability analysis based on ELSM formulations is proposed in the paper (Section 3.2), which uses the FEM results of the code described in Section 2. This method is applied on the basal stability analysis of the two braced excavations studied below (Section 4-5), as well as compared with the Terzaghi (1943) and Bjerrum \& Eide (1956) methods.

\subsection{New method for basal-heave stability analysis}

The proposed method (computer program) for basalheave stability analysis calculates, at any stage of the problem, the safety factor, $F$, along a large number of potential failure surfaces (defined with criterion, as explained below) and searches for the most unfavourable surface, i.e. the surface with the lowest value of $F$.

Figure 3 illustrates, for a particular stage of a problem, different potential failure surfaces that can be defined and automatically generated by the computer program. A small value for $b$ (Fig. 3) should be considered, so that a large number of potential failure surfaces is analysed. As depicted in Fig. 3, the automatically generated surfaces basically differ from each other in their slope behind the wall, since, as shown in several studies of braced excavations (Chen et al., 2015; Do et al., 2016), the most unfavourable failure surface might take an inclined direction on that region of the ground. The $C D$-segment makes an angle of $45^{\circ}$ with the horizontal direction, as well as the $D T$-segment. Point $T$ is the centre of the curve.

For a particular potential failure surface, the proposed method firstly determines the intersection points of the failure line with the edges of the finite elements of the 2Dmesh. Therefore, the failure line is divided into small line segments, each of them located inside of only one of the finite elements of the mesh (Fig. 4).

Thereafter, the average values of the effective stresses $\left(\sigma_{x}, \sigma_{y}, \sigma_{z}^{\prime}\right.$ and $\tau x y$, normal and shear stresses in the $x y z$-space, where $x y$ is the plane of the $2 \mathrm{D}$-finite element analysis) at each of those segments are computed by extrapolating from stresses at the Gauss points of the corresponding finite element.

Considering the failure line divided into line segments, the safety factor is computed by Eq. 5 . $\tau_{i}$ is determined from effective stresses $\sigma_{x}{ }_{x}, \sigma^{\prime}$ and $\tau_{x y}$, known the angle that defines the $i$-segment direction.

Since the soil shear strength varies with consolidation and a critical state model is used in the finite element analysis, $\tau_{f i}$ at each stage is calculated by the following equation of the critical state soil mechanics (Britto \& Gunn, 1987):

$$
\tau_{f i}=\frac{1}{2} M \exp \left(\frac{\Gamma-v_{i}}{\lambda}\right)
$$

where $M$ is given by Eq. 1 , and $v_{i}$, the specific volume of soil at $i$-segment, is determined as follows:

$$
v_{i}=\Gamma-k \ln p_{i}-(\lambda-k) \ln \alpha_{p i}
$$

At the $i$-segment, $p_{i}=\left(\sigma^{\prime}{ }_{x i}+\sigma^{\prime}{ }_{y i}+\sigma_{z i}{ }^{\prime}\right) / 3$ is the effective mean stress and $\alpha_{p i}$ is the $p$-value of the centre of the yield surface in $p-q$ plane (see Fig. 1b), extrapolated from $\alpha_{p}$-values at Gauss points; $\lambda, k$ and $\Gamma$ are parameters of the $p-q-\theta$ model (soil properties), whose meanings are as follows: $\lambda$, slope of normal consolidation line and critical state 

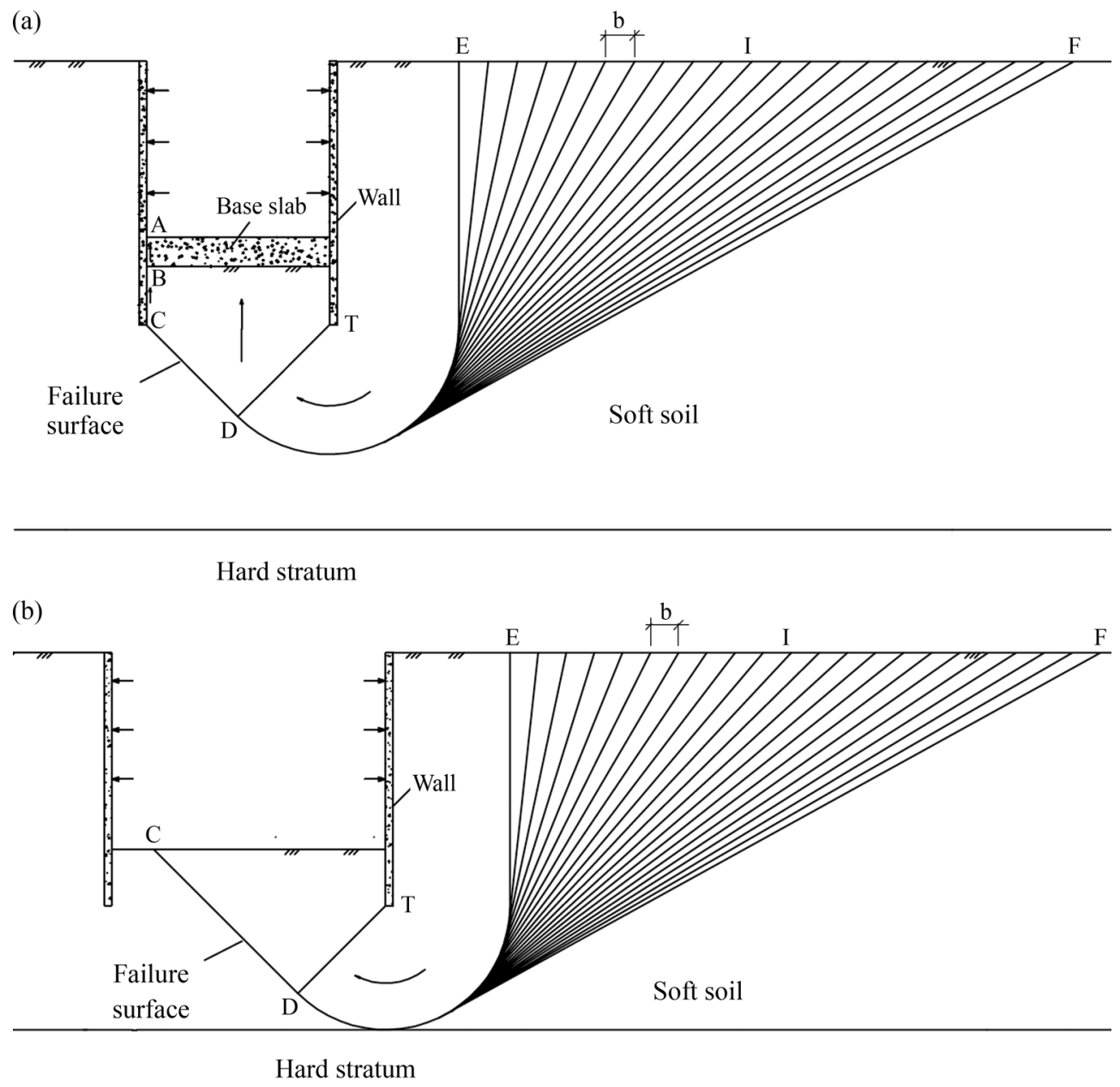

Figure 3 - Potential failure surfaces: a) hard stratum at a large depth; b) hard stratum at a low depth.

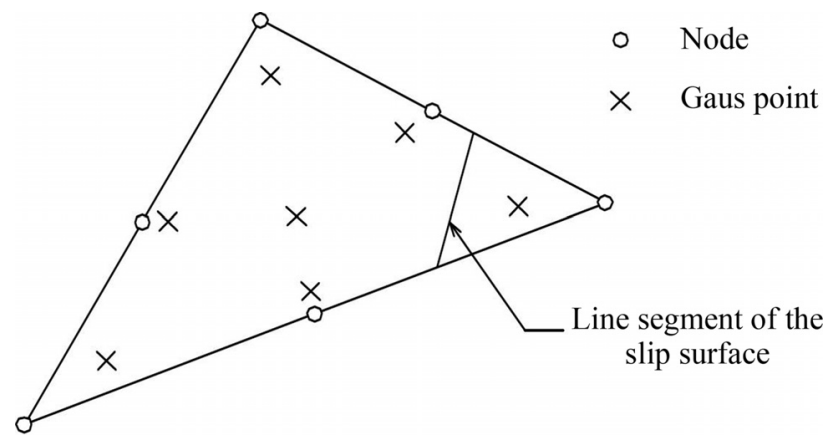

Figure 4 - Six-noded triangular finite element.

line; $k$, slope of swelling and recompression line; $\Gamma$, specific volume of soil on the critical state line at mean normal stress equal to $1 \mathrm{kPa}$.

If a part of the failure surface coincides with a soilwall interface (like the $B C$-segment in Fig. 3a) or a jet-grout base slab-wall interface (like the $A B$-segment in Fig. 3a), $\tau_{f i}$ can be calculated with the following equation:

$$
\tau_{f i}=a_{i}+\sigma_{n i} \tan \delta_{i}
$$

where $a_{i}$ and $\delta_{i}$ are the adhesion and friction angle of the $i$-segment of the soil-wall or jet-grout-wall interface (modelled by joint-elements); $\sigma_{n i}$ is the normal stress on the plane of the $i$-segment.

\section{Description of the Problem}

Two solutions (case A and case B) of a strutted excavation in a soft clay are analysed (Fig. 5), using the above mentioned codes (FEM code and basal-heave stability program). The ground consists of a 35-m-thick soft clay overlying a "hard stratum". The water table is at the ground surface. A jet-grout base slab is considered for case A (Fig. 5), while none jet-grout slab is modelled for case B. All other characteristics of the problem are kept equal for both cases.

The problem comprises a 12-m-deep excavation with width of $14 \mathrm{~m}$ (Fig. 5). The retaining structure is a $1.2 \mathrm{~m}$-thick diaphragm wall of reinforced concrete with length of $19 \mathrm{~m}$ ( $7 \mathrm{~m}$ embedded below the excavation base). The excavation is carried out in a total time of 24 days at a uniform rate. A $2.0 \mathrm{~m}$-thick jet-grout slab is considered in case A (constructed with secant columns, before the exca- 


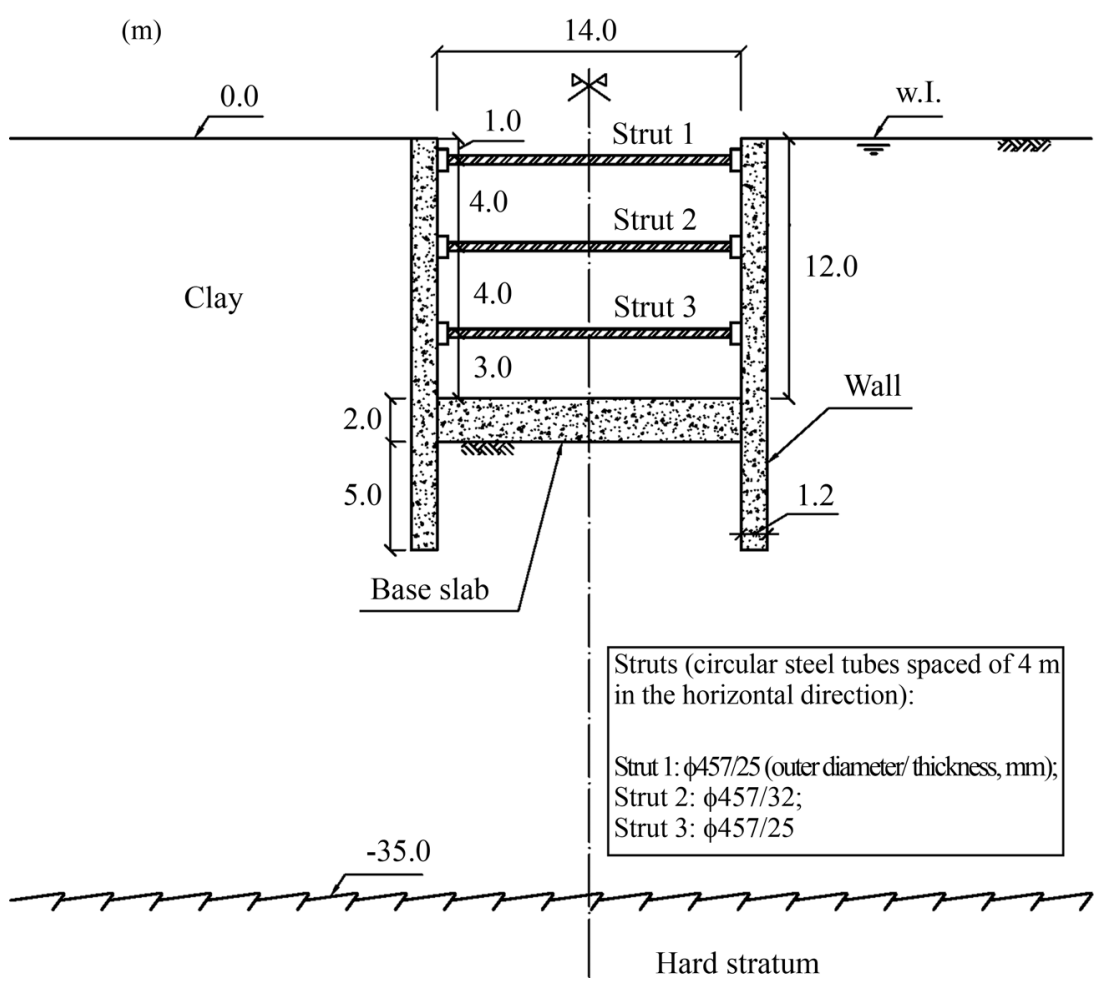

Figure 5 - Cross section of the excavation (case A).

vation) to support the wall below the excavation base. None jet-grout slab is modelled for case B, as said.

In case A, "dissipation holes" in the jet-grout slab (see Fig. 6a) are constructed after the excavation in order to avoid long term overpressures on the lower face of the slab. Therefore, it is assumed that, after the end of excavation, the water flows through the "dissipation holes", being pumped within the excavated area. This corresponds to defining the boundary condition of pore pressure on the lower face of the slab equal to $20 \mathrm{kPa}$ (considering the unit weight of water equal to $10 \mathrm{kN} / \mathrm{m}^{3}$ and that the thickness of the slab is $2.0 \mathrm{~m})$.
Circular steel tubes, spaced $4 \mathrm{~m}$ in the horizontal direction, are used for the struts, whose sections are indicated in Fig. 5.

Basically, for the present cases, the finite element code uses the following features: a) plane strain conditions; b) fully coupled formulation of the flow and equilibrium equations with soil constitutive relations formulated in effective stresses - Biot consolidation theory (Borges, 1995; Lewis and Schrefler, 1987; Britto and Gunn, 1987); c) $p-q-\theta$ critical state model to simulate the constitutive behaviour of soil (Borges, 1995; Lewis and Schrefler, 1987); (a)

(a)

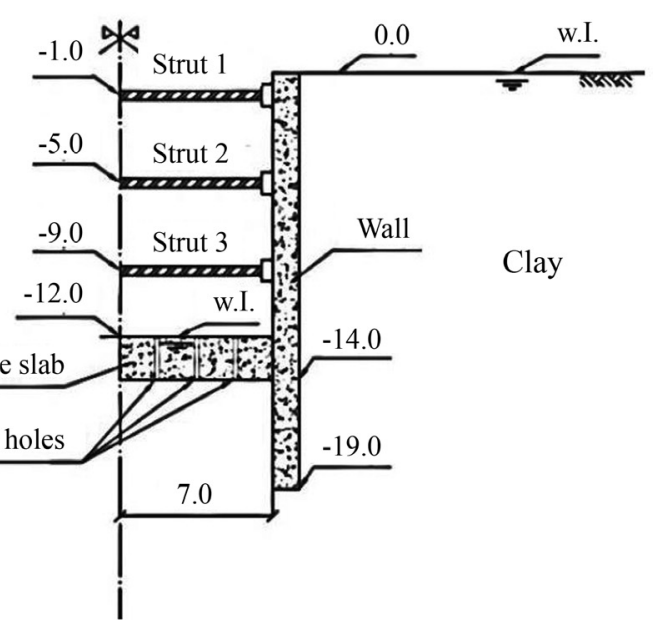

(b)

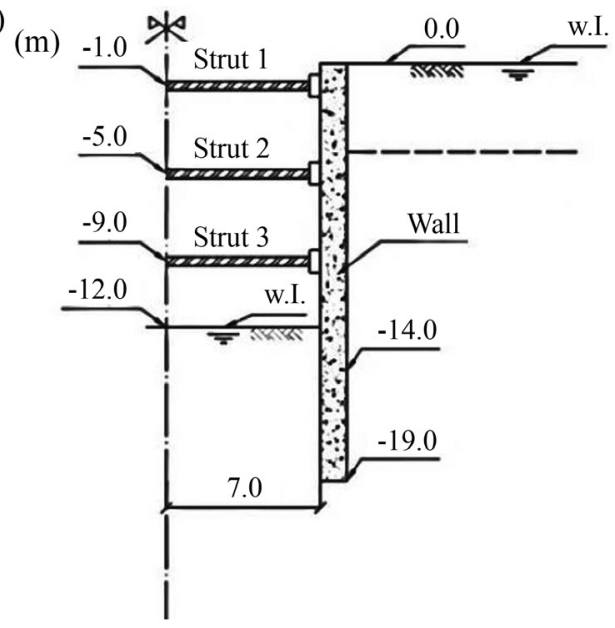

Figure 6 - Hydraulic boundary conditions: a) case A (with base slab); b) case B (without base slab). 
d) elastic linear model to simulate the reinforced concrete wall, the jet-grout slab and the steel struts; e) joint elements with elastic-perfectly plastic behaviour to simulate the slab-wall interfaces.

The values of the $p-q-\theta$ critical state model for the soft clay are indicated in Table 1 ( $\lambda$, slope of normal consolidation line and critical state line; $k$, slope of swelling and recompression line; $\Gamma$, specific volume of soil on the critical state line at mean normal stress equal to $1 \mathrm{kPa} ; N$, specific volume of normally consolidated soil at mean normal stress equal to $1 \mathrm{kPa} ; \phi$, angle of shearing resistance defined in effective terms). Table 2 shows other geotechnical properties of the clay: $\gamma$, unit weight; $v$ ', Poisson's ratio for drained loading; $k_{h}$ and $k_{v}$, coefficients of permeability in horizontal and vertical directions. Table 3 indicates for the clay the variation with depth of the at-rest earth pressure coefficient, $K_{0}$, and undrained shear strength, $c_{u}\left(\sigma^{\prime}\right.$, at-rest vertical effective stress). The clay is moderately over-consolidated from the surface to the depth of $4 \mathrm{~m}$ and normally consolidated from $4 \mathrm{~m}$ to the hard stratum. The values adopted for the clay are similar to those used by Finno $e t$ al. (1991) regarding an excavation in soft soils constructed in Chicago, USA.

Figure 7 shows the finite element mesh of the problem. Two types of the six-noded triangular element are considered: (i) the coupled element, for the clay elements where consolidation is considered; (ii) the non-coupled element, for the wall and jet-grout slab elements. All six nodes of the coupled element have displacement degrees of freedom while only the three vertex nodes have excess pore pressure degrees of freedom. The six nodes of a noncoupled element have only displacement degrees of freedom.
Table 1 - Parameters of the $p-q-\theta$ critical state model.

\begin{tabular}{cccccc}
\hline & $\lambda$ & $\kappa$ & $N$ & $\Gamma$ & $\phi^{\prime}\left({ }^{\circ}\right)$ \\
\hline Soft clay & 0.18 & 0.025 & 3.16 & 3.05 & 26 \\
\hline
\end{tabular}

Table 2 - Geotechnical properties of the clay.

\begin{tabular}{cccc}
\hline & $\gamma\left(\mathrm{kN} / \mathrm{m}^{3}\right)$ & $v^{\prime}$ & $k_{x}=k_{y}(\mathrm{~m} / \mathrm{s})$ \\
\hline Soft clay & 16 & 0.25 & $10^{-10}$ \\
\hline
\end{tabular}

Table 3 - At-rest earth pressure coefficient and undrained shear strength of the clay.

\begin{tabular}{lcc}
\hline Depth $(\mathrm{m})$ & $K_{0}$ & $c_{u}(\mathrm{kPa})$ \\
\hline $0-4$ & $0.9-0.5$ & $13-6.7$ \\
$\geq 4$ & 0.5 & $0.28 \sigma^{\prime}{ }^{\circ}$ \\
\hline
\end{tabular}

The struts are modelled with three-node bar elements with linear elastic behaviour, with a Young's modulus of $206 \mathrm{GPa}$ for the steel. However, due to the difference usually observed in practice between theoretical and effective strut stiffness, the latter was considered equal to half the theoretical stiffness, as suggested by O'Rourke (1992).

Six-node joint elements, with elastic-perfectly plastic behaviour, are used to simulate the interface between the jet-grout base slab and the wall, assuming that a thin portion of soil remains between these two materials. Taking into account the results of laboratorial tests performed by Matos Fernandes (1983), the interface strength was considered equal to the shear strength of the soft soil at the same depth and the elastic tangential stiffness was established as-

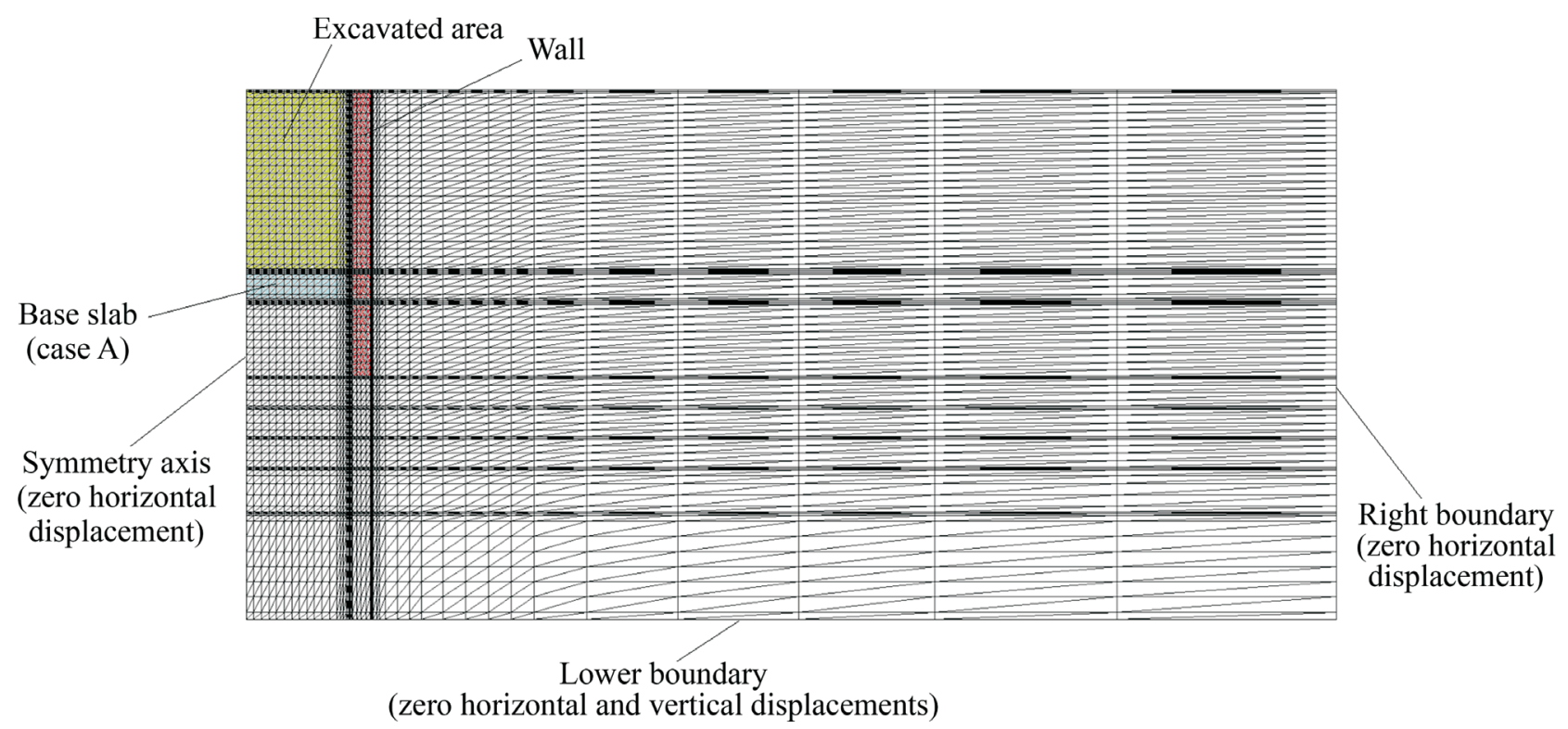

Figure 7 - Finite element mesh. 
suming a tangential displacement of $1 \mathrm{~mm}$ required for the shear strength mobilization.

Regarding the boundary conditions, no horizontal displacement is allowed on the vertical boundaries of the mesh, while the bottom boundary ("hard stratum", at depth of $35 \mathrm{~m}$ ) is completely fixed in both the vertical and horizontal directions. The left vertical boundary corresponds to the symmetry plan of the problem. In hydraulic terms, it is assumed that, in the unexcavated side, the water level remains at the ground surface (which is a conservative and simplified assumption and presupposes that there is a flow that provides water into the ground). On the excavated side, the water level coincides, at each stage of excavation, with the excavation base (which means that the water, inside the excavated area, is assumed to be pumped). A fully coupled analysis is performed both during and after the excavation period.

The 1.2-m-thick wall is modelled as an isotropic elastic material with a Young's modulus $(E)$ of $18 \mathrm{GPa}$ and a Poisson's ratio ( $v$ ) of 0.2. The isotropic elastic model is also considered for the jet-grout slab with the values of $150 \mathrm{MPa}$ and 0.2 for $E$ and v, respectively. The value of $E$ is the same as that mentioned by Jaritngam (2003) for the jet-grout columns constructed in a clayey soil.

The excavation was modelled removing sequentially 1-m-thick layers of finite elements within the area of excavation (see Fig. 7); 2 days of construction, at a uniform rate, was the time considered for each layer.

\section{Analysis of Results}

Theoretically, during the excavation period, because of the very low permeability of the soft soil, the behaviour of the problem can be considered as undrained. Increments of pore pressure and effective stress take place with the excavation process, whose magnitudes depend on both the soil properties and the total stress path, as explained below. Figure 8 illustrates the theoretical stress transfer in an un- drained triaxial test with an extension stress path (as in an excavation, below its base) (Borges, 1995), where compression and tension stress increments are considered as positive and negative, respectively. Skempton's $A$ parameter represents the influence of the soil properties and takes positive values lower than 0.7 in lightly to moderately over-consolidated clays (Lambe \& Whitman, 1969). In an extension stress path, as expected, the increment of pore pressure, $\Delta u$, is negative. Basically, since total mean stress reduces but the volume of soil does not change (undrained behaviour), negative increments of pore pressure are therefore generated. On the other hand, the equilibrium of stresses also determines that $\Delta \sigma^{\prime}{ }_{1}$ is negative (tension increment) while $\Delta \sigma^{\prime}{ }_{3}$ is positive (compression increment). This is what usually happens during the construction period in an excavation of a saturated clay, below its base (which is corroborated by the numerical results of the present study, as shown below). When the soil behaves elastically (as approximately happens in the early stages of an extension stress path), Skempton's $A$ parameter takes the theoretical value of $1 / 3$.

Figure 9 shows colour maps of the pore pressure increments at the end of excavation for cases A and B. Increment of pore pressure is defined herein as the difference between pore pressure at a particular instant and its initial hydrostatic value before excavation.

The results show that negative increments of pore pressures are generated during the excavation, as expected. For both cases, the highest negative value of the increments occurs below the excavation base near the left boundary (symmetry plan), being higher for case B (without base slab). This is explained by the highest decrease of total mean stress associated to the excavation, which occurs on that zone. However, such decrease is smaller for case A due to the slab-wall interaction (shear stresses), which determines that a smaller decrease of total mean stress is trans-

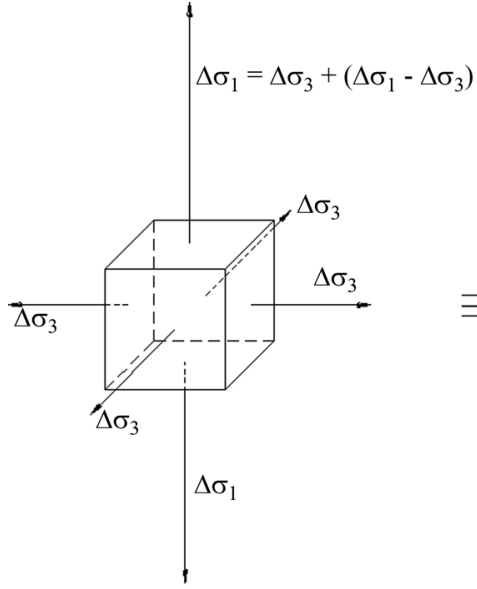

Total stress

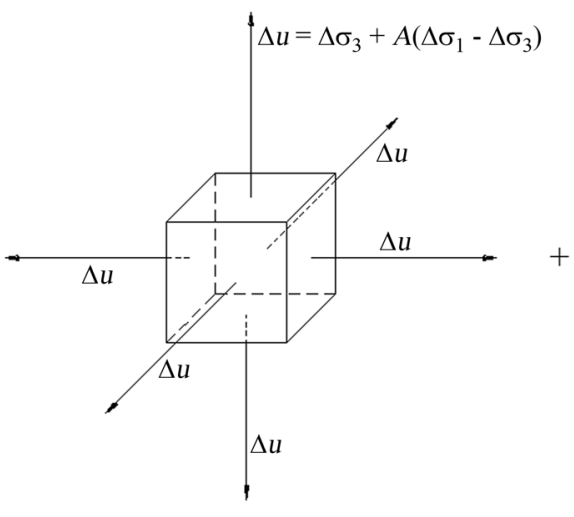

Pore pressure

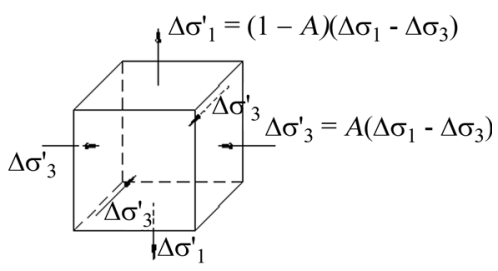

Effective stress

Figure 8 - Theoretical stress increments in an undrained triaxial test with an extension stress path. 

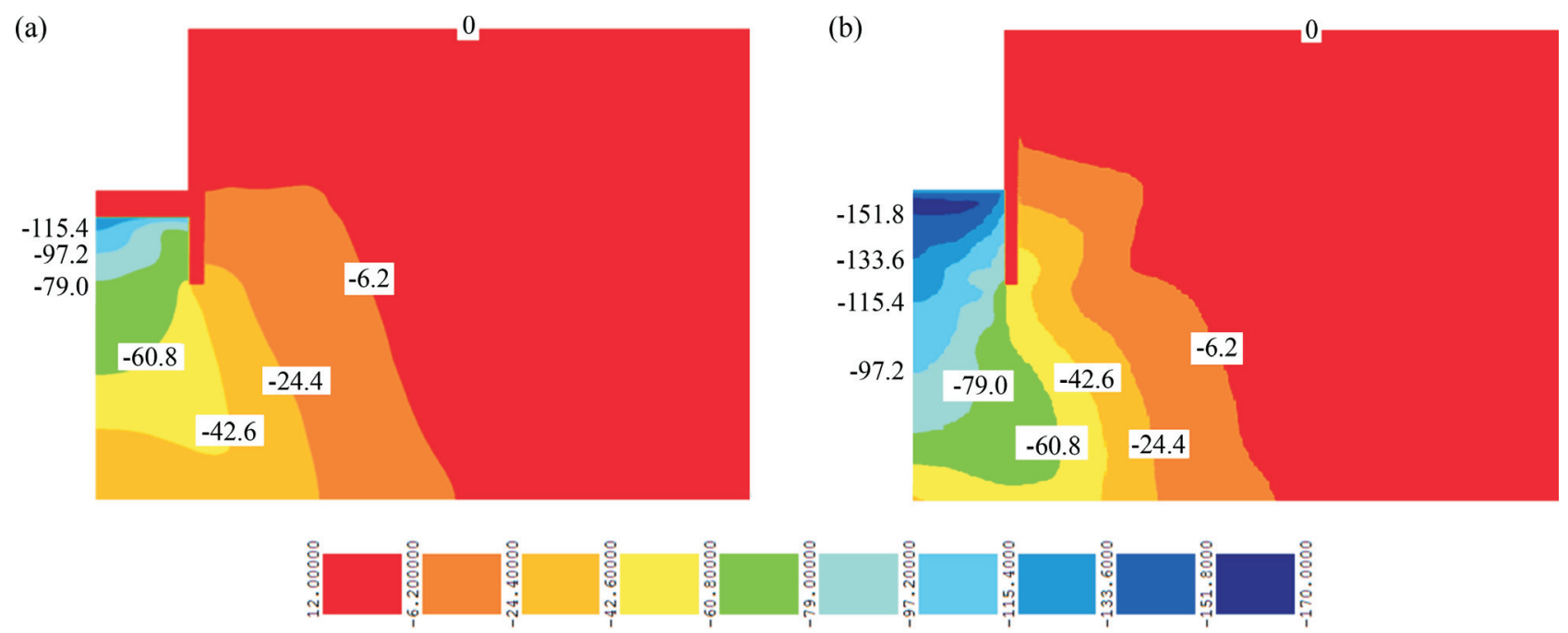

Figure 9 - Increments of pore pressure at the end of excavation (kPa): a) with base slab (case A); b) without base slab (case B).

mitted to the soil under the slab and, therefore, smaller negative increments of pore pressures are generated.

On the unexcavated side, a tendency for generating negative increments is also observed, although with lower values than on the excavated side, for a lower decrease of total mean stress occurs on that side. In case A, the jet-grout slab, which supports the wall below the excavation base, contributes to a lower decompression on the unexcavated side and, therefore, lower negative increments of pore pressures are generated on that side.

Colour maps of pore pressure increments at the end of consolidation (long term distributions) are shown in Fig. 10. After the excavation period, the geotechnical behaviour of the problem is globally determined by the consolidation process, which is dependent on both the magnitude of the pore pressure increments at the end of excavation and the long term hydraulic conditions. Since the values of pore pressure at the end of consolidation are different from its initial values before excavation (due to the water

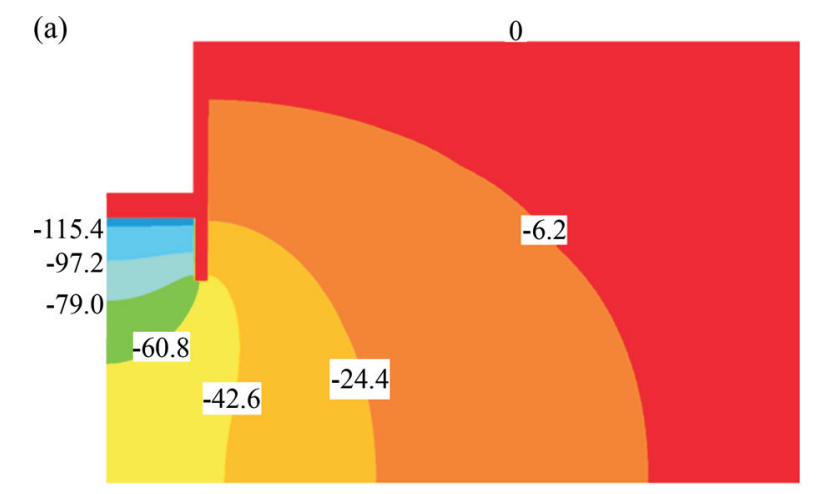

Figure 10 - Increments of pore pressure at the end of consolidation (kPa): a) with base slab (case A); b) without base slab (case B).

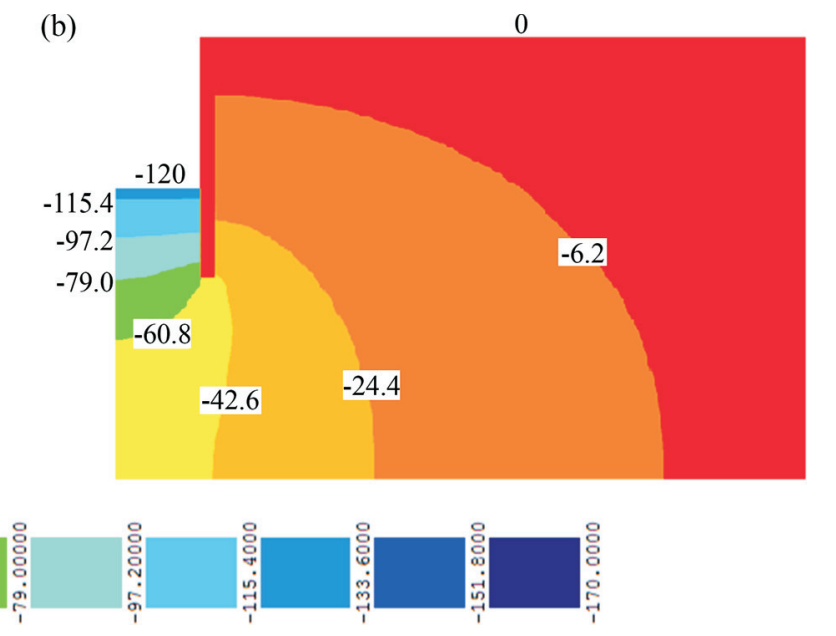

table lowering on the excavated side), the consolidation process is only determined by the dissipation of the difference between pore pressure at the end of excavation and pore pressure at the end of consolidation. Comparing Figs. 9 and 10, the most significant variations in response to the consolidation are observed for case B on the excavated side under the excavation base, where water pressure increases (reduction of the negative value of increments of pore pressure). At the end of consolidation, very similar shapes of isovalue curves of increments of pore pressure are observed for both cases. These curves are perpendicular to the flow lines of the steady water flow (from the supported side to the excavated side, passing under the lower wall tip) that is reached at end of consolidation.

In order to complement the understanding of the consolidation process for both cases, Figs. 11 and 12 show colour maps of the differential pore pressure at several stages after the construction period. The differential pore pressure is defined herein as the difference between pore pressure at 

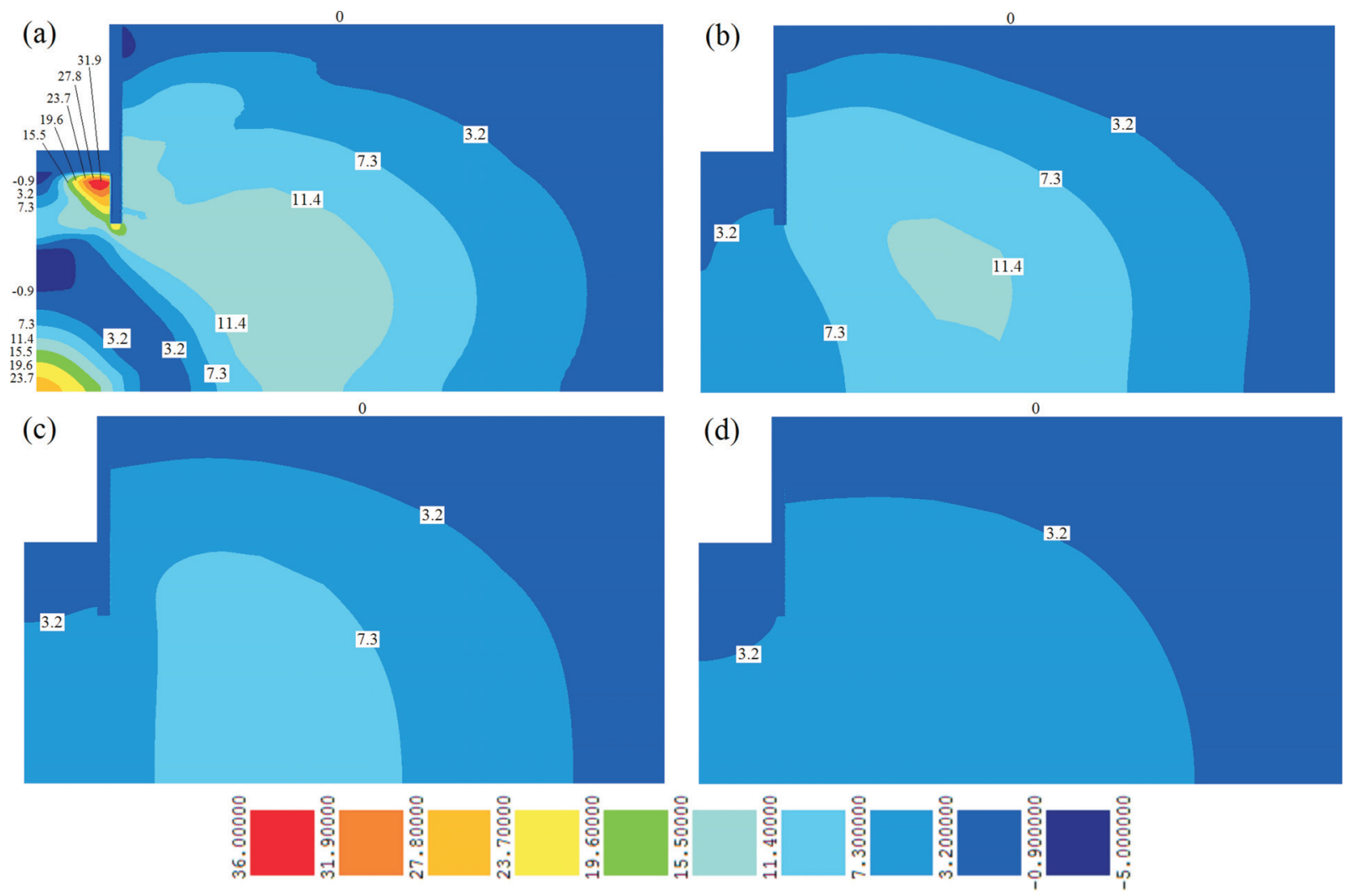

Figure 11 - Differential pore pressure ( $\mathrm{kPa}$ ) for case A (with base slab), at several stages: a) end of construction; b) 6 months after the end of construction; c) 2 years after the end of construction; d) 5 years after the end of construction.
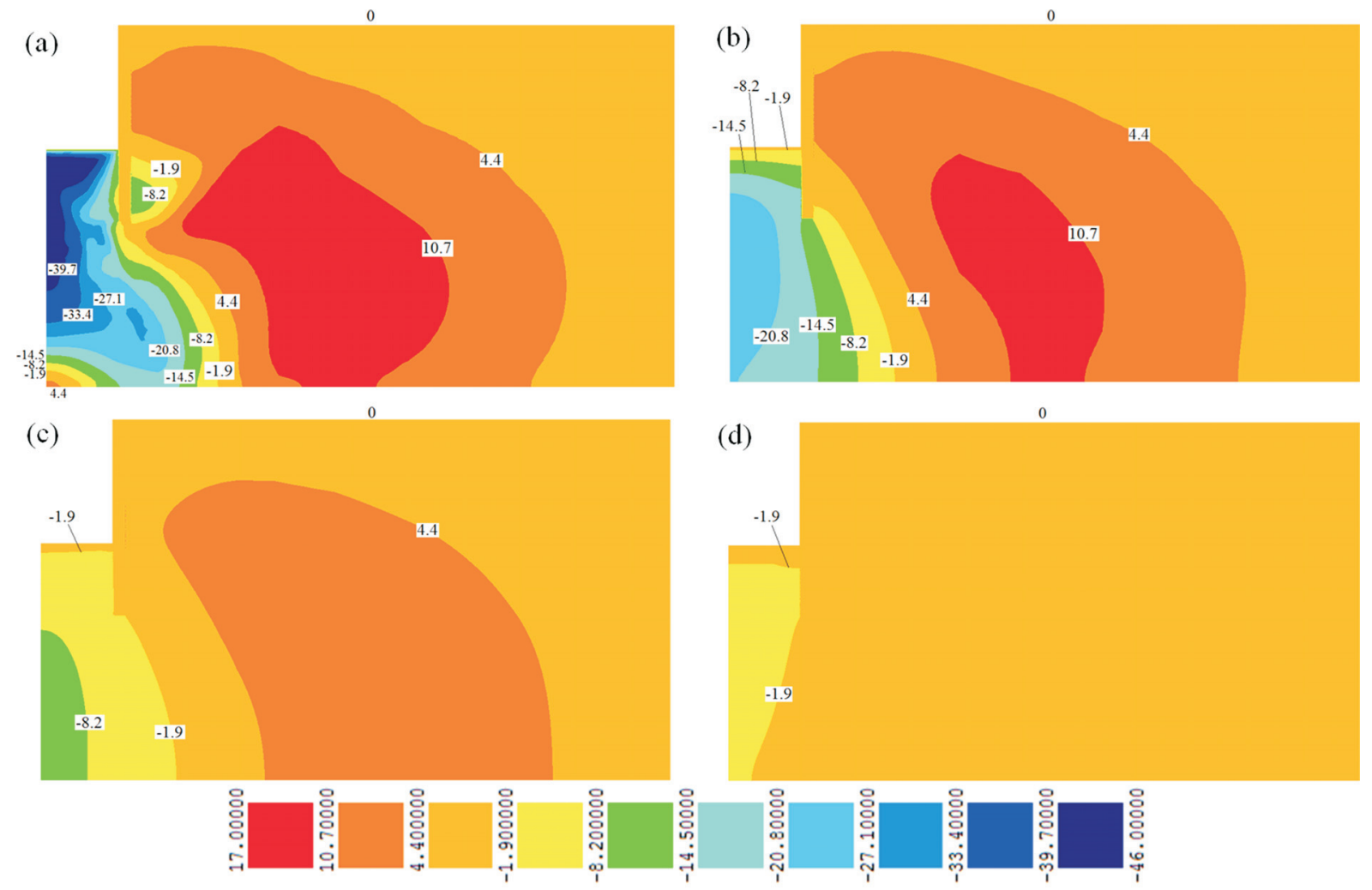

Figure 12 - Differential pore pressure (kPa) for case B (without base slab), at several stages: a) end of construction; b) 6 months after the end of construction; c) 2 years after the end of construction; d) 5 years after the end of construction. 
a particular instant and its long-term value at the end of the consolidation.

From the comparison of the results of Figs. 11 and 12, one can corroborate that, in response to the consolidation, the pore pressure globally decreases for case A, more significantly on the excavated side, while, for case B, it increases on the excavated side and on a region of the supported side near the wall, below the excavation base level.

Principal effective stresses at the end of the excavation are shown in Fig. 13 for both cases. Rotations of the principal stress directions on both sides of the wall, mainly below the excavation base level, are observed in both cases, which means that large shear stress (deviatoric stress) occurs in those regions. However, smaller shear stress (i.e. smaller rotation of the principal stress directions) is observed for case A, which is due to the support effect of the jet-grout slab below the excavation base.

Complementing Fig. 13, Fig. 14 shows colour maps of the stress level, $S L$, in the ground for both cases. The stress level, $S L$, measures the proximity to the soil critical state and is defined as follows:

$$
S L=\frac{q}{p \cdot M}
$$

where $p$ is the effective mean stress, $q$ the deviatoric stress and $M$ the parameter which defines the slope of the critical state line in the $p-q$ plane, as said above (Section 2). In normally consolidated soils, $S L$ varies from zero to 1 , the latter

\section{(a)}

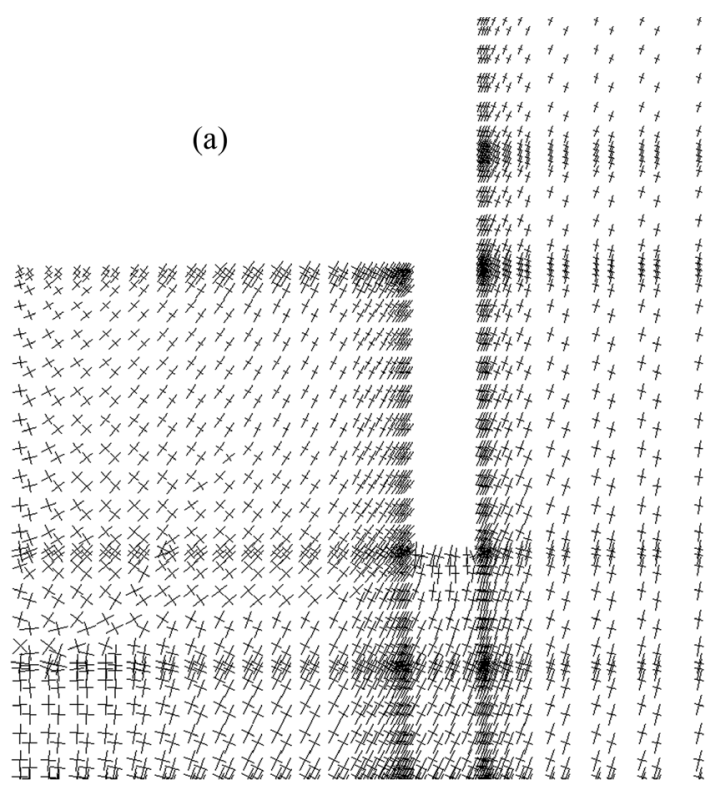

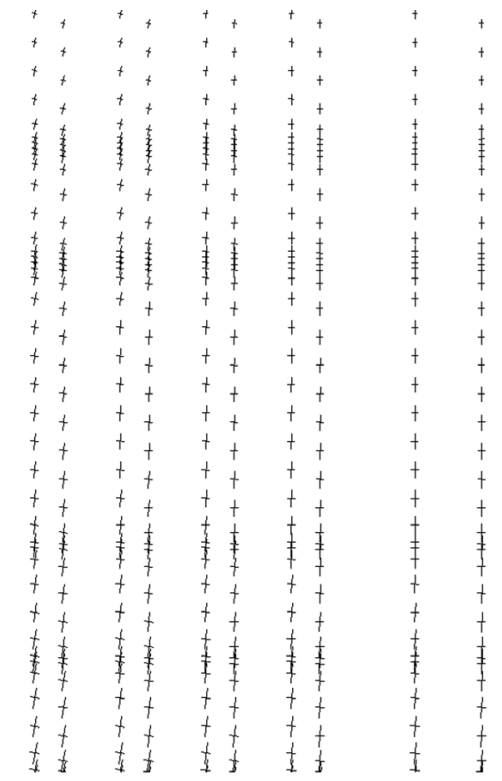

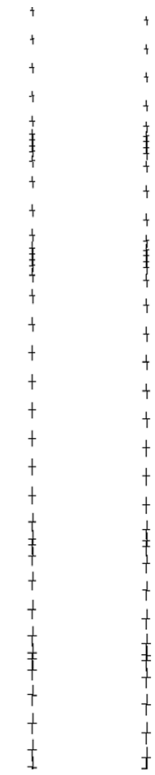

(b)

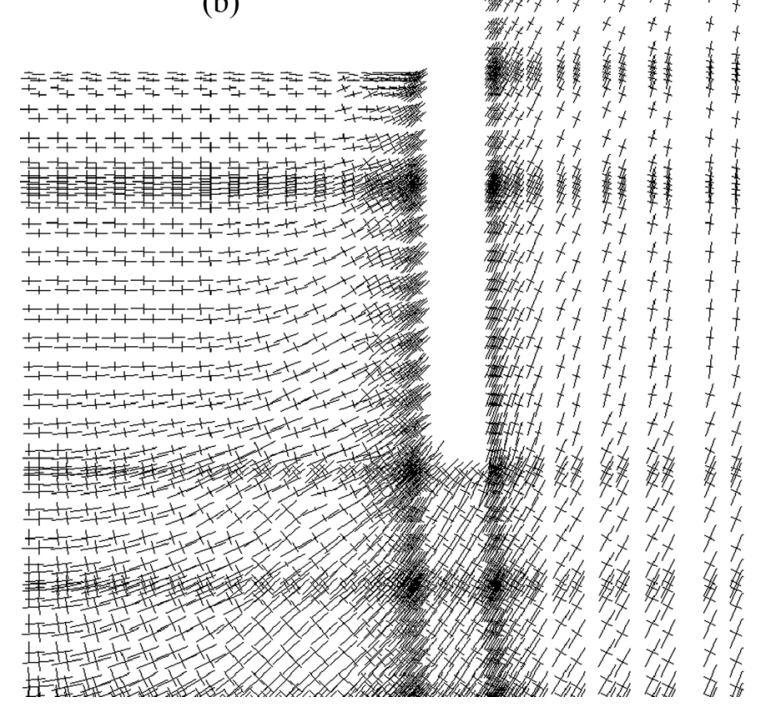

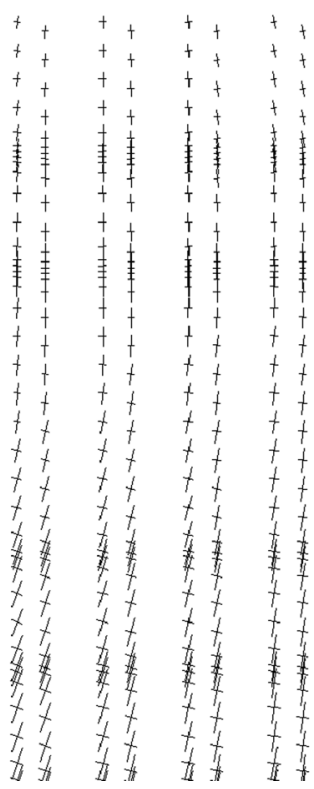


being the critical state level. In over-consolidated soils, because of the peak strength behaviour, the stress level may be higher than 1 .

Figure 14 shows that $S L$ significantly increases during excavation, which is basically related with the increase of the deviatoric stress mentioned above. As expected, at the end of the excavation, higher values of $S L$ are observed for case $\mathrm{B}$ on both sides of the wall below the excavation base level. For this case, in the supported side, the area in critical state extends to larger distances from the wall. However, a contrary effect is observed behind the wall near the ground surface, where $S L$ is lower for case B. As shown below, this effect is related to the profile of the wall horizontal displacement for both cases, which takes smaller values near the ground surface for case B, although much higher values for this case are observed for depths larger than $2 \mathrm{~m}$. These differences in the wall displacement profiles determine different stress redistribution within the soil, which induces the mentioned effect in $S L$.

Calculated from the finite element (FE) results with the computer program for basal-heave stability analysis described in Section 3.2, Fig. 15 depicts, at several stages of excavation, the values of safety factor $(F)$ for both cases A and $\mathrm{B}$, as well as $F$ obtained by the classical Terzaghi

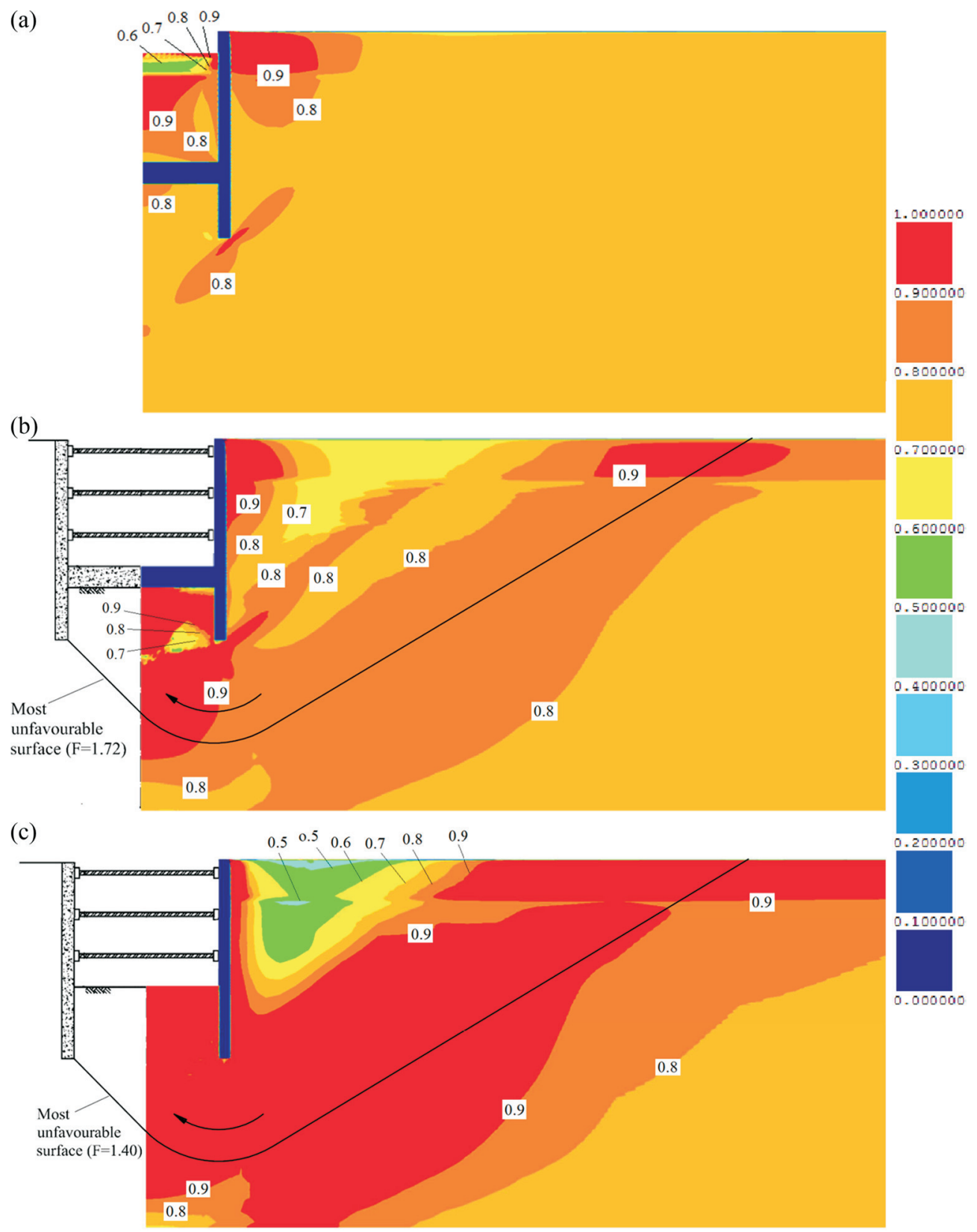

Figure 14 - Stress level: a) Case A (with base slab) at 2m excavated; b) Case A (with base slab) at the end of excavation; b) Case B (without base slab) at the end of excavation. 
(1943) and Bjerrum \& Eide (1956) methods. With regard to the FE analysis, Fig. 15 shows the safety factor is significantly increased by the incorporation of the jet-grout base slab ( $F$ takes values of 1.72 and 1.40 for cases $\mathrm{A}$ and $\mathrm{B}$ respectively, at the end of the excavation; the most unfavourable surface obtained, which is identical for both cases, is also shown in Fig. 14). This clearly corroborates that, by reducing the stress level of the soft soil (as seen above), incorporating a soil-cement slab below the excavation base also implies that a significant increase in stability occurs. As expected, Fig. 15 also shows that such influence on the stability is not captured by the Terzaghi (1943) and Bjerrum \& Eide (1956) methods, since their values of $F$, similar for both methods, are also very similar to those obtained from the FE analysis for case B (without base slab) but, therefore, significantly different from those of case A (with base slab). As said in Section 3.1, this is a conclusion that reinforces the importance of using more complex methods, like

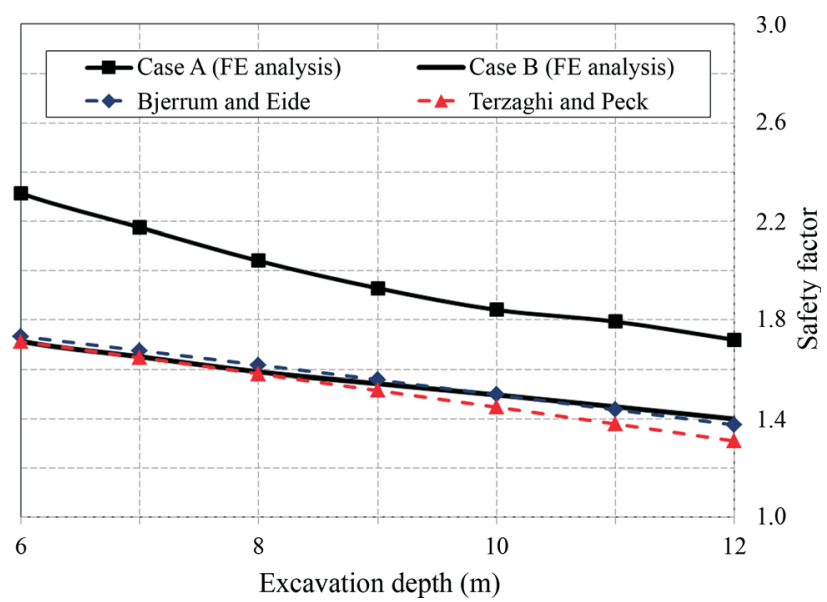

Figure 15 - Safety factor against bottom heave for cases A (with slab) and B (without slab) obtained from the FE analyses. Comparison with Terzaghi (1943) and Bjerrum \& Eide (1956) methods. the one presented in this study based on FE analysis and ELSM formulations, whose results incorporate the influence of the retaining system stiffness, so that more accurate results can be reached.

Figure 16 shows the evolution in time of the safety factor in response to the consolidation process after the end of the excavation for both cases $\mathrm{A}$ and $\mathrm{B}$, calculated from the FE results. These results show that $F$ does not change significantly with time for both cases (although it reduces with time in the case without base slab, from a maximum of 1.40 to a minimum of 1.34), which reflects that the ratio of the acting shear stress sum to the shear strength sum along the most unfavourable surface is not significantly influenced by the consolidation process in the present excavation.

Diagrams of the wall horizontal displacement are shown in Fig. 17 for both cases. As expected, these results show that the wall displacement is much larger in the case without the base slab (case B), which corroborates the significant support effect of such structural element. In case B,

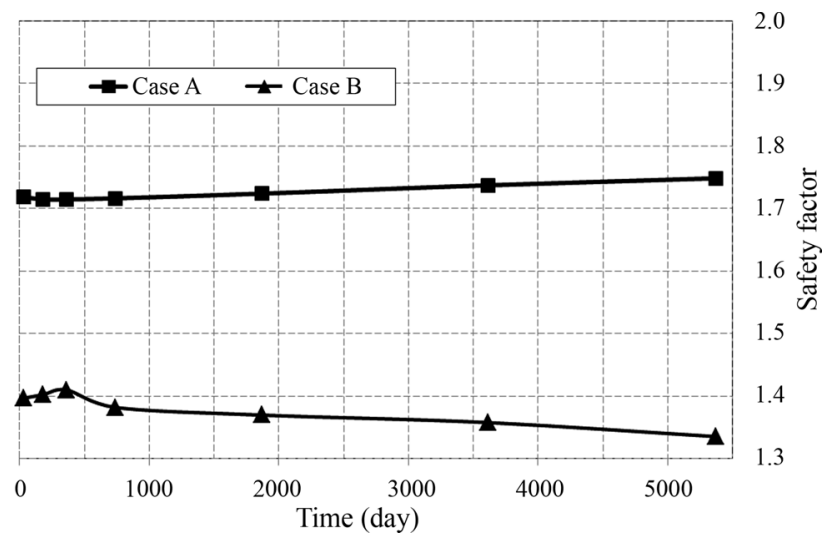

Figure 16 - Safety factor against bottom heave at several stages after the end of excavation for cases A and B (FE analysis).

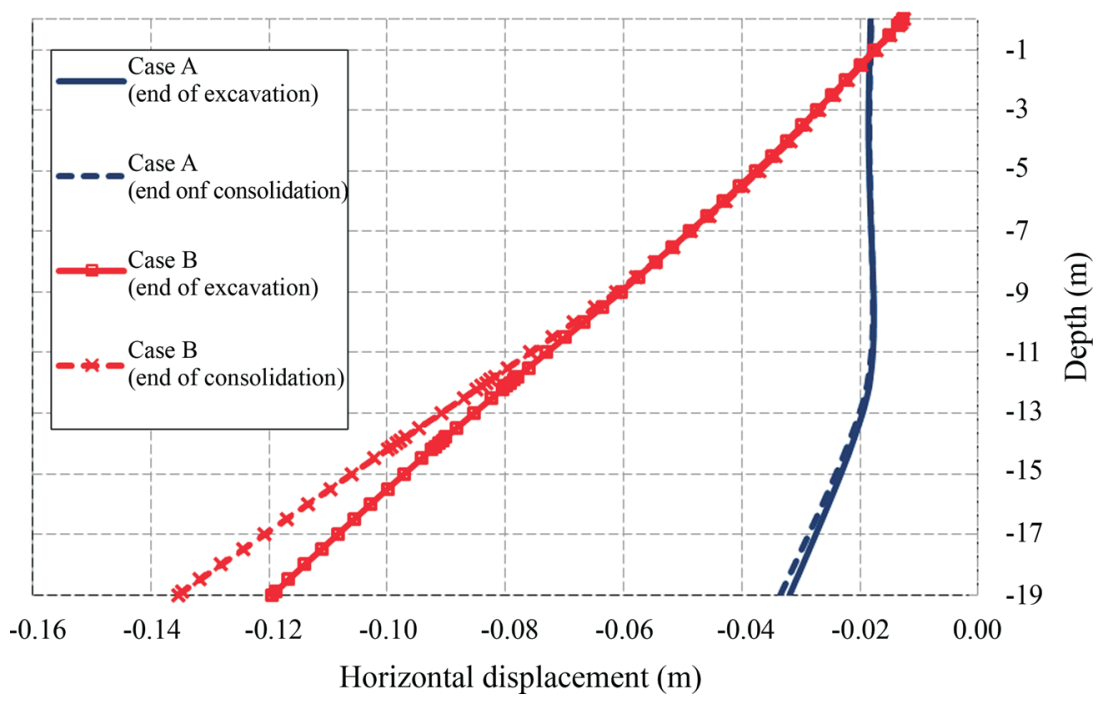

Figure 17 - Wall horizontal displacement at the end of excavation and end of consolidation for cases A and B. 
in overall terms, the wall rotates with centre at the top of the wall (a typical behaviour when there is no ground treatment below the excavation base), while, for case A, the horizontal displacement is approximately uniform from the top to $12 \mathrm{~m}$ depth (level of the base slab). In case A, the embedded depth of the wall takes a typical behaviour of a cantilever, supported on the jet-grout slab. Figure 17 also shows that the wall displacement increases in response to the consolidation, mainly for case B below the excavation base, which is related to the reduction of earth pressure on the excavated side face of the wall, as explained below.

Earth pressure in terms of horizontal stress (i.e. pore pressure plus horizontal effective stress) on the wall faces is depicted in Fig. 18, at the end of excavation and at the end of consolidation, for both cases. Earth pressure on the excavated side is depicted as negative while on the supported side it is depicted as positive. In response to the excavation, on the supported side face, there is no significant variation of earth pressure from the top to approximately $10 \mathrm{~m}$ depth, while a significant reduction is observed for larger depths (where the wall displacement is larger, as shown in Fig. 17). This reduction is larger for the case without base slab, since the horizontal displacement of the wall is larger. As to the post-excavation period, the earth pressure on the supported side face practically does not change in response to the con- solidation, which is due to the contrary variations of pore pressure and horizontal effective stress that globally tend to compensate each other.

As to the excavated side, the earth pressure reduces with the excavation for both cases, as expected, because of the soil decompression on that side. Since the horizontal displacement of the wall towards the excavated side is larger for the case without slab (case B), the earth pressure on the excavated side face is larger in this case. Regarding the post-excavation period, a reduction of earth pressure with the consolidation occurs on the excavated side for both cases, although its magnitude is not very high for case A. Similar values of the earth pressure are observed, at the end of consolidation, for both cases.

In order to analyse how the pore pressure and the horizontal effective stress separately act on the wall faces, Fig. 19 depicts their results for both cases at the end of excavation and at the end of consolidation. Values on the excavated side are depicted as negative while on the supported side they are depicted as positive.

On the excavated side face, pore pressure significantly reduces in response to the excavation for both cases, although this reduction is larger for the case without base slab (case B). On this face, pore pressure also decreases in response to the consolidation for case $\mathrm{A}$, while a small con-

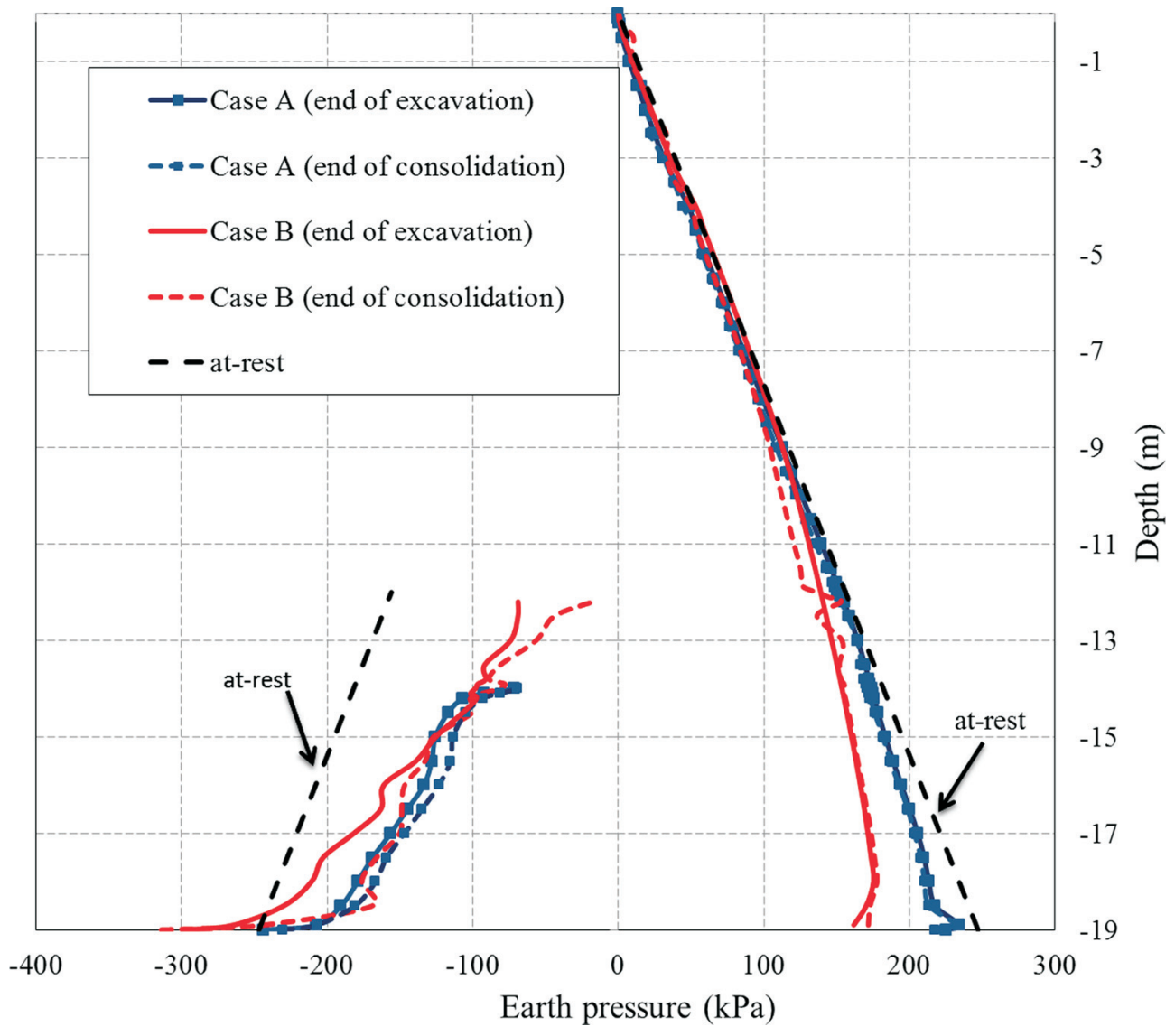

Figure 18 - Earth pressure on the wall faces at the end of excavation and at the end of consolidation for both cases (with and without base slab). 

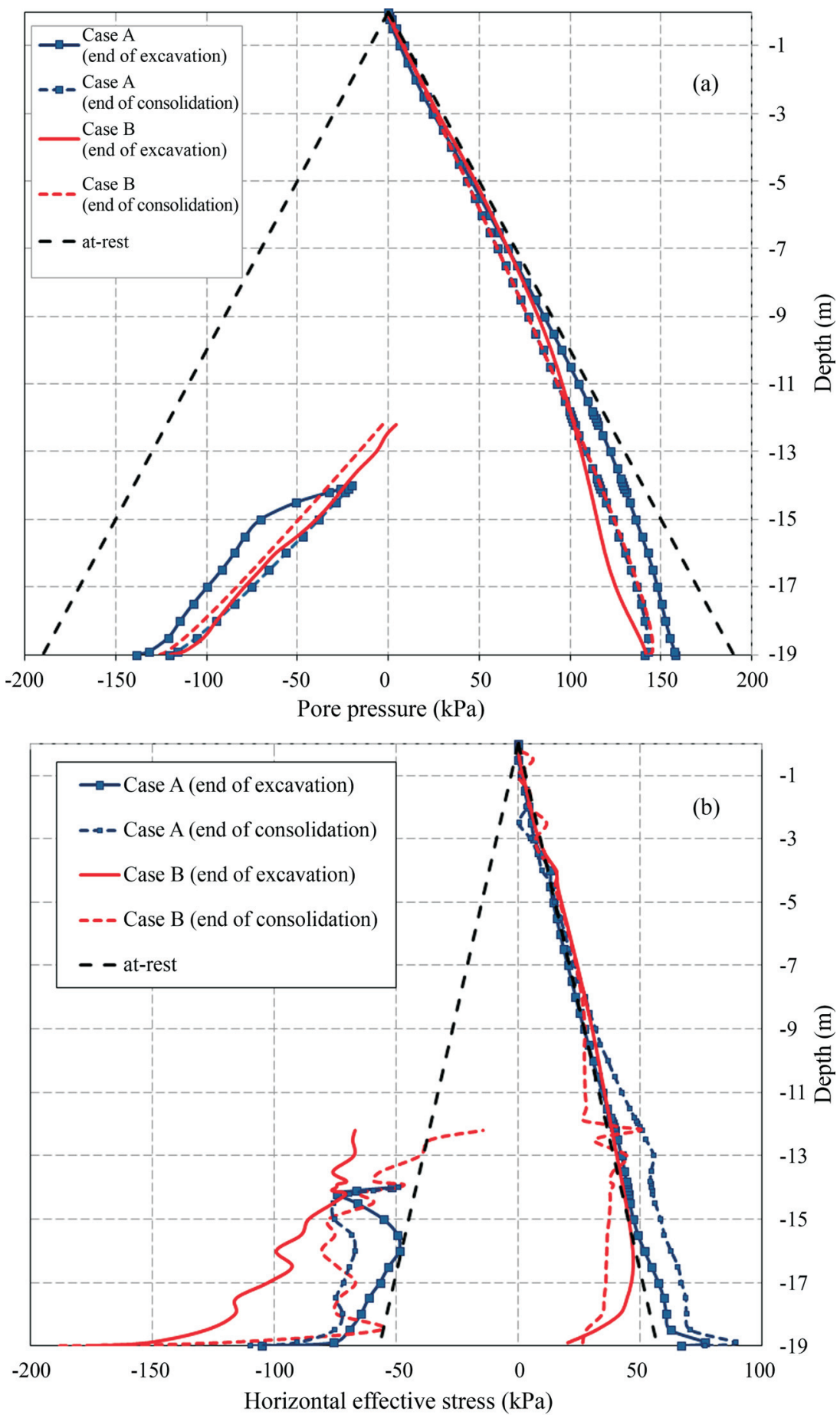

Figure 19 - Pore pressure (a) and horizontal effective stress (b) on the wall faces at the end of excavation and at the end of consolidation for both cases (with and without base slab).

trary effect is observed for case B. Since long-term values of pore pressure are similar for both cases, this contrary effect is due to the difference of values at the end of excavation.

On the supported side face, a reduction of the pore pressure is also observed in response to the excavation, although with less magnitude than on the excavated side face.
This reduction is also larger for the case without base slab. As to the effects of the consolidation on both cases, they are qualitatively similar to those on the excavated side face, i.e. pore pressure also reduces for case A, while a contrary effect is observed for case B (for depths larger than $12 \mathrm{~m}$ ). At the end of consolidation, pore pressure on the supported side face takes smaller values than its initial hydrostatic 


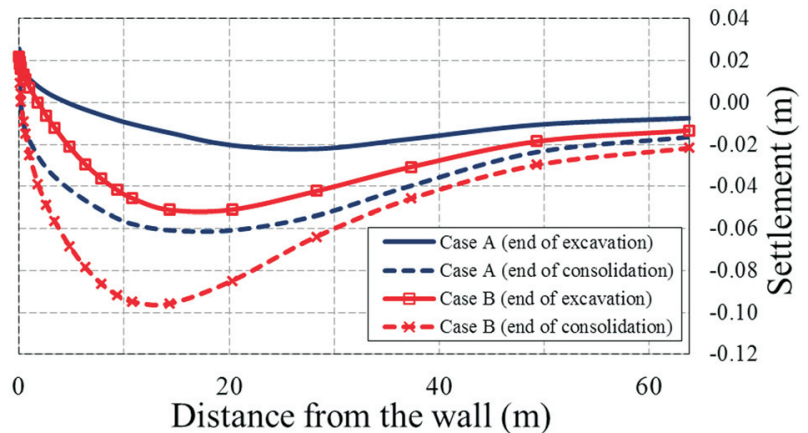

Figure 20 - Settlements of the ground surface of the unexcavated side at end of excavation and end of consolidation for cases A and B.

values, which is related to the downward water flow that occurs behind the wall, as mentioned above.

As to the horizontal effective stress on the wall faces, Fig. 19b shows that its values significantly increase in response to the excavation on the excavated side face for case $\mathrm{B}$; the same effect also occurs for case A although with less magnitude. As expected, this fact is in consonance with the theoretical scheme of Fig. 8, since, in global terms, extension stress paths take place below the excavation base. In response to the consolidation, the horizontal effective stress on the excavated side face reduces for case B since pore pressure increases, while the contrary effect occurs for case A.

Regarding the horizontal effective stress on the supported side face, its evolution in response to the excavation is different for both cases, mainly for depths larger than $9 \mathrm{~m}$. For case A (with base slab) the evolution is qualitatively similar to that on the excavated side face, i.e. the hor- izontal effective stress increases as pore pressure declines. For case B, both the pore pressure and the horizontal effective stress reduce. This effect is mainly due to the much larger horizontal displacement of the wall towards the excavation side for the case without slab (see Fig. 19). In response to the consolidation, the evolution is qualitatively similar to that on the excavated side face, i.e. the horizontal effective stress reduces for case B since pore pressure increases, while the contrary effect occurs for case A.

Figure 20 shows the surface settlements of the unexcavated side. These diagrams have the typical concave shapes and are directly related to the wall horizontal displacements. The settlement is much higher for case B. The maximum value at the end of consolidation increases about $60 \%$ when compared to case A. Figure 20 also shows that, in response to the consolidation, there are significant downward displacements at the surface in both cases, which is determined not only by the increase of the wall displacements with the consolidation (more significant for case B, as shown above), but also by the reduction of soil volume in that side determined by the decrease of pore pressure (more significant for case A).

Figure 21 shows the diagrams of the wall bending moment for cases A and B. As expected, the presence of the jet-grout slab determines that the shape of the diagram is different (since the wall has one extra support). The maximum negative moment occurs near the base slab for case A while it occurs near the strut 2 (at the end of the excavation period) and strut 3 (at the end of consolidation) for case B. In the post-excavation period, the bending moment diagram does not significantly change for case A, while a sig-

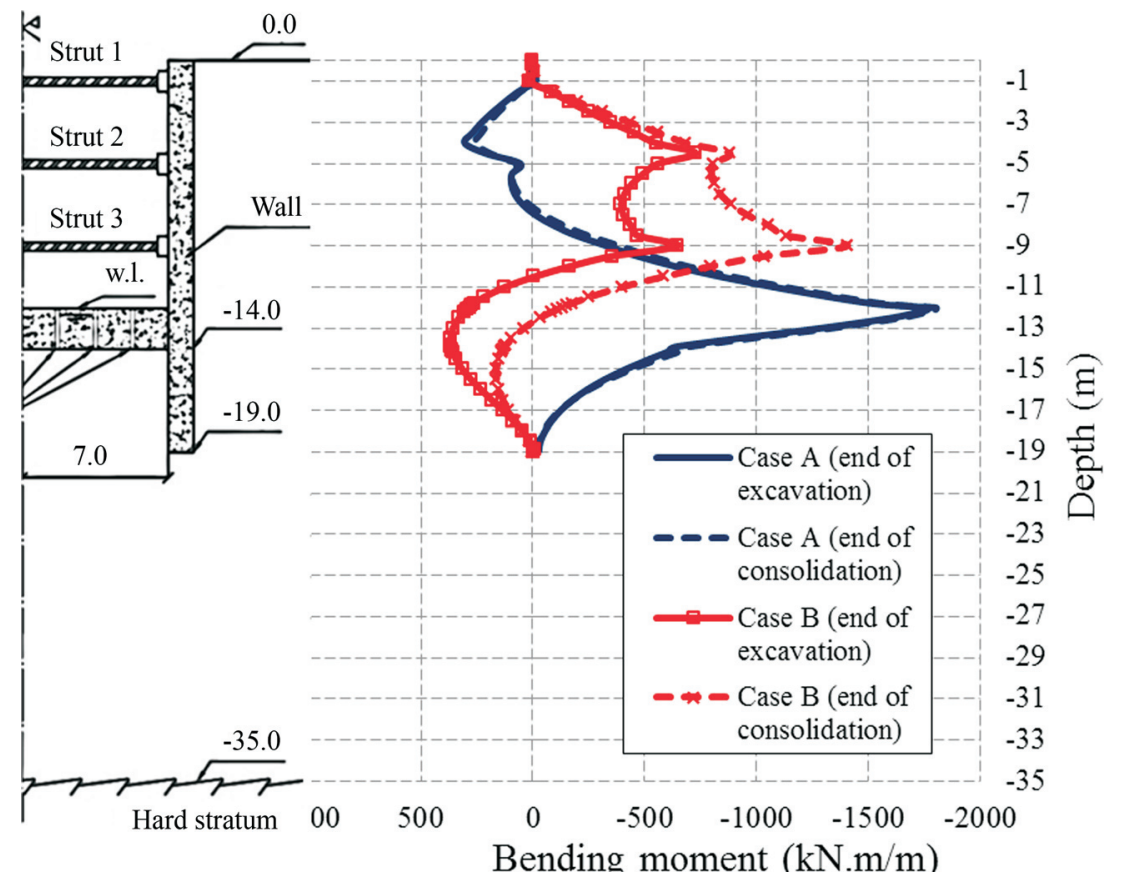

Figure 21 - Wall bending moment at end of excavation and end of consolidation for cases A and B. 
nificant increase of the negative values and reduction of the positive values are observed for case B; this is directly related to the variation of the earth pressure on the wall, where a significant reduction on the excavated side face for case B was observed (Fig. 19), as commented above.

The horizontal compression load in the jet-grout slab for case A is illustrated in Fig. 22. This figure shows that the compression load does not significantly change in response to consolidation, which is also consistent with previous comments on the earth pressure on the wall faces for case A, which also does not significantly change during the post-excavation period (Fig. 18).

\section{Conclusions}

A strutted excavation in soft soil incorporating a jetgrout base slab was analysed through a computer code based on the finite element method and using a new method for basal stability analysis that utilizes the results of the finite element code. Fully mechanical-hydraulic coupled analysis was considered, as well as the $p-q-\theta$ critical state model for soil constitutive behaviour. Two cases of the same problem, with and without soil-cement bottom slab, were compared. The following conclusions can be highlighted:

(1) The incorporation of the jet-grout slab improved the excavation stability against bottom failure, as well as it significantly reduced the wall displacements and settlements of the supported ground.

(2) As expected, the effect of the soil-cement slab on the excavation stability was not captured by the classical limit equilibrium methods of Terzaghi (1943) and Bjerrum \& Eide (1956) - their results for safety factor revealed to be similar to those obtained from the FE analysis for the case without slab but significantly different from those of the case with slab. This reinforces the importance of using more complex methods for excavation bottom stability analysis, like the one presented in this study, based on the finite element method and formulations of the "enhanced limit slope stability method".

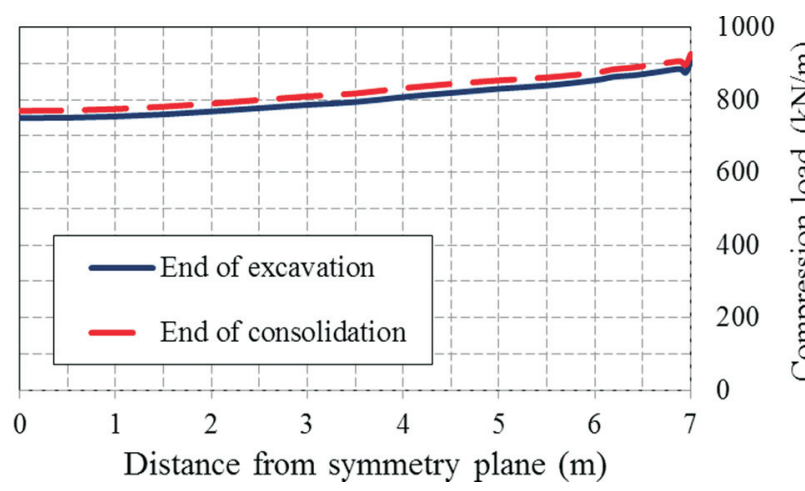

Figure 22 - Compression load in the jet-grout slab at end of excavation and end of consolidation for case $\mathrm{A}$.
(3) In response to the consolidation, significant downward displacements on the supported soil surface occurred for both cases (with and without slab), which are basically related with the wall displacements and the reduction of soil volume determined by the decrease of pore pressure on the supported side - associated to the downward flow of the water behind the wall, due to the water table lowering on the excavated side.

(4) Safety against bottom failure did not significantly change after the end of excavation in response to consolidation, although there was a reduction of safety factor, from of 1.40 to 1.34 , during the post-excavation period, for the case without slab.

\section{References}

Alves, A.N. (2012). Cylindrical Diaphragm Walls in Deep Excavations in Soft Soils. M.Sc. Thesis, University of Porto, Portugal (in Portuguese).

Azevedo, M.S. (2010). Cylindrical Excavations in Soft Soils Retained by Slurry Walls. M.Sc. Thesis, University of Porto, Portugal (in Portuguese).

Barros, L. (2015). Berlin-Type Retaining Walls Combined with Jet-Grout or Cutter Soil Mixing Walls: Analysis by the Finite Element Method. M.Sc. Thesis, University of Porto, Portugal (in Portuguese).

Basset, R.H. (1986a). The instrumentation of the trial embankment and of the Tensar SR2 grid. Proc. Prediction Symposium on a Reinforced Embankment on Soft Ground, King's College, London.

Basset, R.H. (1986b). Presentation of instrumentation data. Proc. Prediction Symposium on a Reinforced Embankment on Soft Ground, King's College, London.

Bjerrum, L. \& Eide, O. (1956). Stability of strutted excavations in clay. Géotechnique, 6(1):32-47. https://doi.org/10.1680/geot.1956.6.1.32

Borges, J.L. (1995). Geosynthetic-Reinforced Embankments on Soft Soils. Analysis and Design. Ph.D. Thesis in Civil Engineering, Faculty of Engineering, University of Porto, Portugal (in Portuguese).

Borges, J.L. (2004). Three-dimensional analysis of embankments on soft soils incorporating vertical drains by finite element method. Computers and Geotechnics, 31(8):665-676. https://doi.org/10.1016/j.compgeo.2004.11.001

Borges, J.L. (2008). Cut slopes in clayey soils: Consolidation and overall stability by finite element method. Geotechnical and Geological Engineering, 26(5):479-491. https://doi.org/10.1007/s10706-008-9182-7

Borges, J.L. \& Alves, A. (2014). Deep cylindrical excavations in soft soils retained by reinforced concrete diaphragm walls: Analysis considering the consolidation effect. Proc. 8th European Conference on Numerical Methods in Geotechnical Engineering, Delft, The Netherlands, pp. 717-722. 
Borges, J.L. \& Cardoso, A.S. (2002). Overall stability of geosynthetic-reinforced embankments on soft soils. Geotextiles and Geomembranes, 20(6):395-421. https://doi.org/10.1016/S0266-1144(02)00014-6

Borges, J.L. \& Guerra, G.T. (2014). Cylindrical excavations in clayey soils retained by jet grout walls: Numerical analysis and parametric study considering the influence of consolidation. Computers and Geotechnics, 55(1):42-56. https://doi.org/10.1016/j.compgeo.2013.07.008

Britto, A.M. \& Gunn, M.J. (1987). Critical Soil Mechanics Via Finite Elements. Ellis Horwood Limited, England.

Cai, F.; Ugai, K. \& Hagiwara, T. (2002). Base stability of circular excavations in soft clay. Journal of Geotechnical and Geoenvironmental Engineering, 128(8):702-706. https://doi.org/10.1061/(ASCE)1090-0241(2002)128:8 (702)

Chen, R.P.; Lee, Z.C.; Chen, Y.M. \& Ou, C.Y (2015). Failure investigation at a collapsed deep excavation in very sensitive organic soft clay. Journal of Performance of Constructed Facilities, ASCE, 29(3):04014078. https://doi.org/10.1061/(ASCE)CF.1943-5509.000055 7

Clough, G.W. \& Hansen, L.A. (1981). Clay anisotropy and braced wall behaviour. J. Geotech. Engrg. Div., 107(7):893-913.

Clough, G.W. \& Reed, M.W. (1984). Measured behaviour of braced wall in very soft clay. Journal of Geotechnical Engineering Division, ASCE, 110(1):1-19. https://doi.org/10.1061/(ASCE)0733-9410(1984)110:1 (1)

Costa, P.A. (2005). Braced Excavations in Soft Clayey Soils - Behaviour Analysis Including the Consolidation Effects. M.Sc. Thesis, Faculty of Engineering, University of Porto, Portugal (in Portuguese).

Costa, P.A.; Borges, J.L. \& Fernandes, M.M. (2007). Analysis of a braced excavation in soft soils considering the consolidation effect. Geotechnical and Geological Engineering, 25(6):617-629. https://doi.org/10.1007/s10706-007-9134-7

Do, T.N.; Ou, C.Y. \& Chen, R.P. (2016). A study of failure mechanisms of deep excavations in soft clay using the finite element method. Computers and Geotechnics, 73(2016):153-163.

https://doi.org/10.1016/j.compgeo.2015.12.009

Domingues, T.S. (2006). Foundation Reinforcement with Stone Columns in Embankments on Soft Soils: Analysis and Design. M.Sc. Thesis, Faculty of Engineering, University of Porto, Portugal (in Portuguese).

Faheem, H.; Cai, F.; Ugai, K. \& Hagiwarab, T. (2003). Two-dimensional base stability of excavations in soft soils using FEM. Computers and Geotechnics, 30:141-163.

https://doi.org/10.1016/S0266-352X(02)00061-7
Faheem, H.; Cai, F. \& Ugai, K. (2004). Three-dimensional base stability of rectangular excavations in soft soils using FEM. Computers and Geotechnics, 31:67-74. https://doi.org/10.1016/j.compgeo.2004.02.005

Finno, R.J.; Harahap, I.S. \& Sabatini, P.J. (1991). Analysis of braced excavations with coupled finite element formulations. Computers and Geotechnics, 12(2):91-114. https://doi.org/10.1016/0266-352X(91)90001-V

Guerra, G.T. (2009). Self-Supported Jet-Grout Walls in Cylindrical Sxcavations. M.Sc. Thesis, University of Porto, Portugal (in Portuguese).

Jaritngam, S. (2003). Design Concept of Soil Improvement for Road construction on soft clay. Proc. Eastern Asia Society for Transportation Studies, v. 4, pp. 313-322.

Lade, P.V. \& Duncan, J.M. (1973). Cubical triaxial tests on cohesionless soils. J. Soil Mech. Found. Div., ASCE 99(19): 793-812.

Lambe, T.W. \& Whitman, R.V. (1969). Soil Mechanics. John Wiley and Sons, Inc., New York.

Lewis, R.W. \& Schrefler, B.A. (1987). The Finite Element Method in the Deformation and Consolidation of Porous Media. John Wiley and Sons, Inc., New York.

Liu, S.Y.; Shao, L.T. \& Li, H.J. (2015). Slope stability analysis using the limit equilibrium method and two finite element methods. Computers and Geotechnics, 63:291-298.

https://doi.org/10.1016/j.compgeo.2014.10.008

Mateus, R. (2010). Braced Excavations in Soft Soils Incorporating Jet-Grout Base Slabs and Pre-Stressed Struts. M.Sc. Thesis, University of Porto, Portugal (in Portuguese).

Matos Fernandes, M.M. (1983). Flexible Structures for Earth Retaining: New Design Methods. Ph.D. Thesis in Civil Engineering, Faculty of Engineering, University of Porto, Portugal (in Portuguese).

Matos Fernandes, M.; Cardoso, A.S.; Topa Gomes, A.; Borges, J.L.; Guerra, N.C. \& Antão, A.N. (2012). Deep excavations in urban areas - Finite element modelling for three geotechnical scenarios and retaining solutions. In: Innovative Numerical Modelling in Geomechanics. Taylor \& Francis Group, London, pp. 51-76.

Monteiro, A.S. (2011). Excavations in Clayey Soils Retained by Jet Grout Walls Reinforced with Steel Beams. M.Sc. Thesis, University of Porto, Portugal (in Portuguese).

Mita, K.A.; Dasari, G.R. \& Lo, K.W. (2004). Performance of a three-dimensional Hvorslev-Modified Cam Clay model for overconsolidated clay. International Journal of Geomechanics, ASCE, 4(4):296-309. https://doi.org/10.1061/(ASCE)1532-3641(2004)4:4(2 96)

Nayak, G.C. \& Zienkiewicz, O.C. (1972). Convenient form of stress invariants for plasticity. Journal of the Structural Division, 98(4):949-954. 
O'Rourke, T.D. (1992). Base stability and ground movement prediction for excavations in soft soil. Proc. International Conference on Retaining Structures, Cambridge, pp. 657-686.

Peck, R.B. (1969). Deep excavations and tunnelling in soft ground. Proc. VIIth ICSMFE, Mexico City, General Report, State-of-the-Art Volume, pp. 225-290.

Pinto, M.S. (2011). Excavations Supported by Reinforced Concrete Walls and Slab Bands. M.Sc. Thesis, University of Porto, Portugal (in Portuguese).

Potts, D.M.; Kovacevic, N. \& Vaughan, P.R. (1997). Delayed collapse of cut slopes in stiff clay, Géotechnique, 47(5):953-982. https://doi.org/10.1680/geot.1997.47.5.953

Potts, D.M. \& Zdravkovic, L. (1999). Finite Element Analysis in Geotechnical Engineering - Theory. Thomas Telford, London.

Quaresma, M.G. (1992). Behaviour and Modelling of an Embankment Over Soft Soils Reinforced by Geotextile. Ph.D. Thesis, Université Joseph Fourier, Grenoble I (in French).
Santos, R.M. (2014). Basal-Heave Stability of Strutted Excavations in Soft Soils: Safety Analysis by the Finite Element Method. M.Sc. Thesis, University of Porto, Portugal (in Portuguese).

Skempton, A.W. (1951). The bearing capacity of clays. Proc. Building Research Congress, London, pp. 180-189.

Su, S.F.; Liao, H.J. \& Lin, Y.H. (1998). Base stability of deep excavation in anisotropic soft clay. J. Geotech. Geoenviron. $\quad$ Eng., 124(9):809-819. https://doi.org/10.1061/(ASCE)1090-0241(1998)124:9 (809)

Terzaghi, K. (1943). Theoretical Soil Mechanics. Wiley, New York.

Ukritchon, B.; Whittle, A.J. \& Sloan, S.W. (2003). Undrained stability of braced excavations in clay. Journal of Geotechnical and Geoenvironmental Engineering, 129(8):738-755. https://doi.org/10.1061/(ASCE)1090-0241(2003)129:8 (738)

Yeo, K.C. (1986). Simplified foundation data to predictors. Proc. Prediction Symposium on a Reinforced Embankment on Soft Ground, King's College, London. 